\title{
Nanoscale
}

Check for updates

Cite this: Nanoscale, 2019, 11, 19636

Received 25th June 2019

Accepted 15th September 2019

DOI: 10.1039/c9nr05367k

rsc.li/nanoscale

\section{Surface coatings for solid-state nanopores}

\author{
Olivia M. Eggenberger, (D) Cuifeng Ying (D) and Michael Mayer (D)*
}

\section{Introduction}

In the past two decades, nanopore-based analysis of single biomolecules or nanoparticles has undergone rapid development for the detection and characterization of DNA, proteins, viruses and synthetic nanoparticles. ${ }^{1-13}$ Recent advancements include the development of the portable MinION device for DNA sequencing with protein nanopores, ${ }^{14,15}$ the combination of nanopore recordings with additional modalities for sensing, characterizing, or manipulating molecules such as detecting

Adolphe Merkle Institute, Chemin des Verdiers 4, University of Fribourg, Fribourg, Switzerland.E-mail: michael.mayer@unifr.ch fluorescent molecules based on plasmonic effects, ${ }^{16-22}$ recording changes in the local voltage of a graphene nanoribbon transistor, ${ }^{23}$ or pulling on or holding molecules in a nanopore with optical tweezers. ${ }^{24,25}$

In most cases, the basic experimental setup to detect and characterize single molecules in nanopores comprises two compartments of electrolyte solution, a thin insulating membrane that separates these compartments, and a single pore with a diameter ranging from 1-50 $\mathrm{nm}$ that constitutes the only connection between the two compartments (Fig. 1A). When an electric potential difference is applied across the membrane, molecules move through the electrolyte-filled pore and cause a change in the resistance of the pore by displacement of ions (Fig. 1B). The resulting resistive pulses that

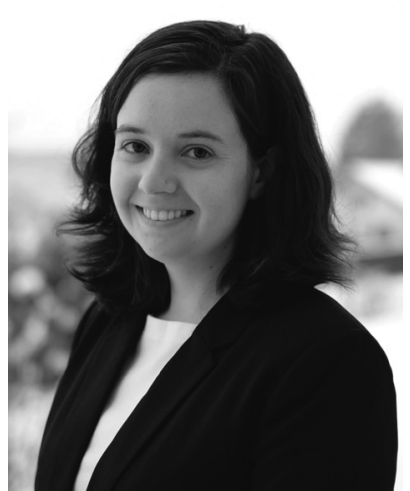

Olivia M. Eggenberger
Olivia Eggenberger is a Ph.D. student at the Adolphe Merkle Institute at the University of Fribourg in the Biophysics group of Prof. Michael Mayer. She received her undergraduate degree from the Department of Physics at Albion College in 2013 and a Master of Science from the Department of Biomedical Engineering at the University of Michigan in 2015. Her research focuses on single protein characterization using lipid-coated synthetic nanopores.

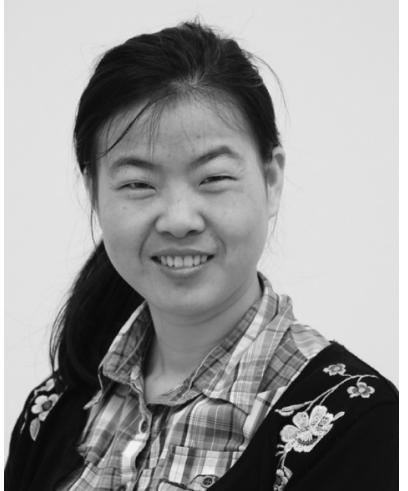

Cuifeng Ying
Cuifeng Ying received her Ph.D in Physics in 2013 from Nankai University in the group of Prof. Jianguo Tian. She is currently working as a postdoctoral researcher at the Adolphe Merkle Institute at the University of Fribourg in the Biophysics group of Prof. Michael Mayer. Her research focuses on characterizing single proteins using nanoplasmonic optical measurements and nanopore technology. 

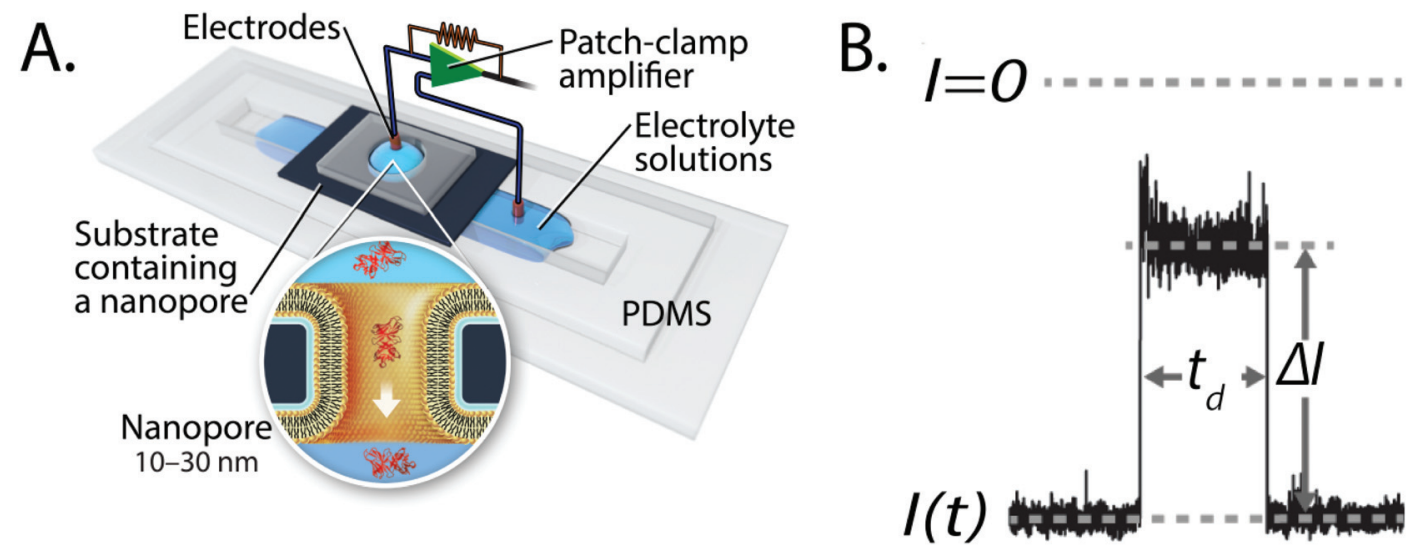

Fig. 1 Basic principles of resistive pulse recordings through nanopores. A. Experimental set-up for resistive pulse recordings using an electrolytefilled nanopore; the inset shows the translocation of a single protein through a nanopore with a lipid-bilayer coating. ${ }^{27}$ Figure from Yusko et al. ${ }^{27}$ B. Example of a resistive pulse; the change in current, $\Delta l$, is proportional to particle volume and the dwell time, $t_{d}$, is inversely proportional to particle charge. Time-dependent modulations of the current during a resistive pulse can reflect the orientation of non-spherical particles and reveal their shape, rotational diffusion coefficient and dipole moment. ${ }^{27}$

coincide with the translocation of individual particles reveal characteristics of that molecule. For instance, the most probable dwell time of the resistive pulse is inversely proportional to the charge of the molecule, while the amplitude of the resistive pulse is related to the volume, shape, and orientation of the molecule in the electric field (Fig. 1B). ${ }^{26}$

There are two major types of nanopores: biological nanopores $^{28-32}$ and synthetic, solid-state nanopores. ${ }^{3,8,33}$ Biological nanopores consist of transmembrane proteins that enable the translocation of molecules through their lumen. ${ }^{34,35}$ The most widely used example of this type of nanopore is the $\alpha$-hemolysin protein that is expressed by Staphylococcus aureus and self-incorporates into lipid

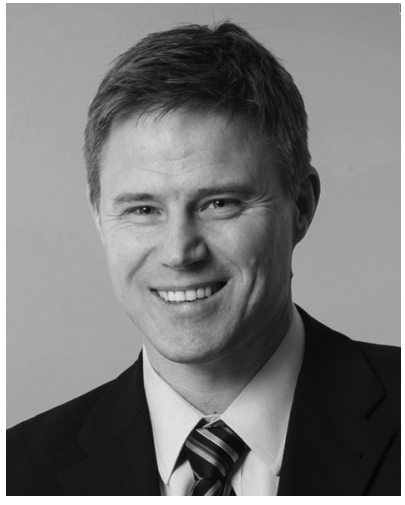

Michael Mayer
Michael Mayer obtained a Ph.D. in biophysical chemistry with Horst Vogel at the Swiss Federal Institute of Technology in Lausanne (EPFL), followed by postdoctoral research with George M. Whitesides at Harvard University. In 2004, he started a faculty position in Biomedical Engineering at the University of Michigan. In 2015 his group moved to the Adolphe Merkle Institute at the University of Fribourg, where he holds the chair of Biophysics. His research takes inspiration from nature to solve problems in biophysics ranging from understanding signaling and transport processes in biological membranes to characterizing protein complexes relevant for neurodegenerative diseases and to engineering biocompatible electrical power sources. membranes. ${ }^{28,36}$ The narrowest constriction of protein pores is relatively small; their diameters typically range from $0.4 \mathrm{~nm}-$ $3.4 \mathrm{~nm} .^{5,6,28,37,38}$ These constrictions enable resistive-pulse recordings with high signal-to-noise ratio, they make protein pores attractive for the detection of analytes with at least one small dimension such as ions, ${ }^{39}$ organic molecules, ${ }^{40}$ peptides and unfolded proteins, ${ }^{41}$ as well as for sequencing of DNA and RNA. ${ }^{42-46}$ Other attractive features of these pores for biophysics and biosensing applications are the availability of crystal structures of several of these pore proteins with atomic resolution, ${ }^{36,47-52}$ their evolved resistance to clogging, ${ }^{29}$ their amenability to site-specific chemical modifications, ${ }^{53,54}$ and the excellent reproducibility of producing these pores by established protein expression and purification methods. ${ }^{28}$ Biological nanopores have, however, three main limitations: first, their small diameters prevent the ability to characterize large molecules. Second, their intrinsic fragility can lead to fluctuations of the baseline current through these pores under certain conditions such as elevated applied potential differences or elevated temperature. ${ }^{6,29}$ And third, the requirement to reconstitute these proteins into a lipid bilayer or polymer membrane poses the challenge to prepare a stable lipid or polymer membrane for each experiment, and to reconstitute protein pores into these membranes efficiently ${ }^{55}$ before each experiment.

The lack of large-scale tunability of the diameter of biological nanopore provided one of the motivations for the development of synthetic nanopores. Synthetic nanopores can be fabricated in virtually any size from below $1 \mathrm{~nm}$ in diameter ${ }^{56}$ to the sub-micrometer range. ${ }^{57,58}$ These sizes allow for the analysis of a large range of biomolecules including proteins, viruses, and nanoparticles. ${ }^{42,59,60}$ Nanoscale pores or channels in solid state materials are fabricated by various techniques ${ }^{61-66}$ including ion beam sculpting, ${ }^{56}$ focused ion beam fabrication, ${ }^{67}$ transmission electron microscopy, ${ }^{68}$ electron beam fabrication, ${ }^{69-73}$ track-etching, ${ }^{74-78}$ dielectric break down, ${ }^{79,80}$ laser-assisted dielectric breakdown, ${ }^{80}$ laser-assisted 

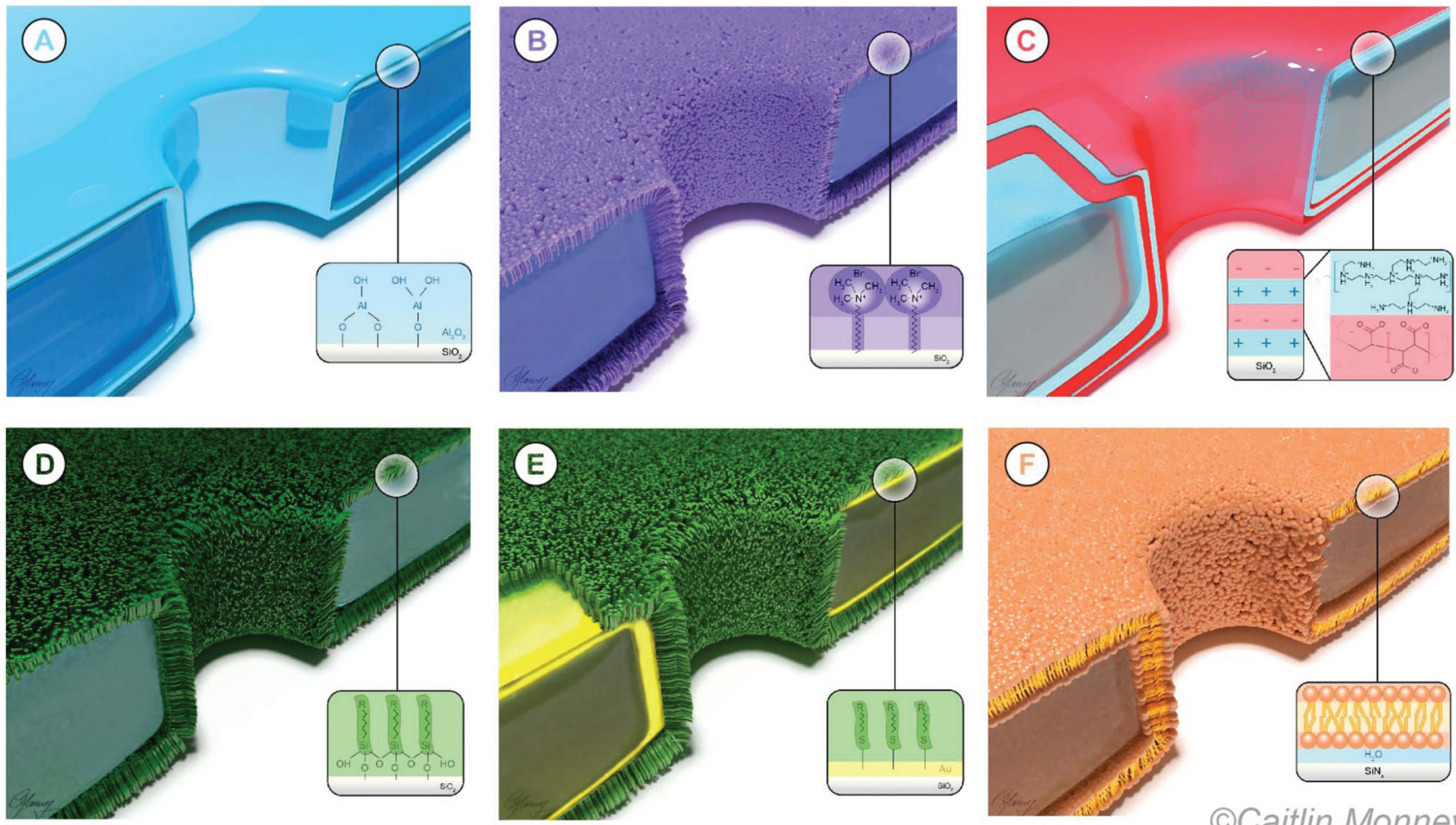

(C) Caitlin Monney

Fig. 2 Idealized cartoon representations of the most commonly employed nanopore coatings. A. Cross-section through a $\mathrm{SiO}_{2} \mathrm{membrane}$ with a coating of $\mathrm{Al}_{2} \mathrm{O}_{3}$ deposited on the membrane and on the walls of the nanopore. $\mathrm{B}$. Coating of a nanopore prepared by physisorption of a surfactant. C. Coating prepared by layer-by-layer self-assembly of negatively and positively charge polymers. D. Coating prepared by silanization. E. Coating of a self-assembled monolayer of alkanethiols on gold. F. Coating of a nanopore with a fluid lipid bilayer.

etching, ${ }^{80-82}$ and layer-by-layer removal. ${ }^{83}$ These techniques make it possible to create nanopores with varying shapes ${ }^{84}$ and surface chemistries ${ }^{85}$ in a range of materials including silicon nitride ${ }^{86,87}$ silicon dioxide, ${ }^{68}$ hafnium oxide, ${ }^{88}$ aluminum oxide, ${ }^{89}$ graphene,$^{90,91}$ glass $^{92-94}$ and polymer films. ${ }^{95,96}$

One major limitation of solid-state nanopores is the tendency of their walls to interact non-specifically with many analytes. These interactions can lead to clogging of the pores and to the inability to translocate additional molecules. In this context, proteins, which constitute an increasingly common analyte in nanopore-based biophysics studies, are particularly prone to interact with the walls of synthetic nanopores. ${ }^{97}$ Factors contributing to these interactions include electrostatic attraction, ${ }^{98-100}$ van der Waals forces, ${ }^{101-103}$ and hydrophobic interactions. ${ }^{97,104-106}$ Surface coatings such as those shown in Fig. 2 can help to reduce the strength of these interactions and thereby allow for unperturbed translocation. ${ }^{107}$

The negatively charged surfaces on the walls of most synthetic nanopores also lead to two phenomena that are relevant for nanopore-based analyses: electroosmotic flow (EOF) and ion current rectification (ICR). Charged surfaces in contact with a liquid electrolyte accumulate a layer of counter-ions forming an electrical double layer (EDL). ${ }^{108}$ When a potential is applied that drops along the length of a nanopore, it drives electrophoretic movement of ions in the EDL creating EOF whereby the liquid moves with the ions. ${ }^{109-111}$ Electroosmotic flow provides an additional force on molecules inside the nanopore, which can either add to the electrophoretic force or point in the opposite direction, depending on the net charge of the molecule and on the polarity of the charges on the nanopore wall. ${ }^{112,113}$ In the context of nanopore sensing, it is important to either minimize EOF as much as possible or to keep it constant at a well-defined level in order to analyze and interpret translocation time distributions from the motion of particles or macromolecules through the pore. ${ }^{27,107,114}$

The second phenomenon that originates from charges at the nanopore wall is ICR, which requires either an asymmetry of the pore geometry or of the distribution of surface charges along the pore's long axis. ${ }^{115-117}$ The resulting asymmetric ion distribution leads to a preferential current flow towards one polarity of the applied electric potential difference compared to the other polarity, leading to non-linear curves of current as a function of applied voltage similar to an electric diode. ${ }^{115,118-123}$ This phenomenon can be exploited for sensing purposes, ${ }^{121,124-126}$ however for applications that benefit from a uniform electric field along the nanopore, ICR should typically be eliminated. ${ }^{80}$ Surface coatings provide a way to increase, reduce or invert surface charges on the walls of nanopores. ${ }^{127-130}$ Tuning the charge density on the nanopore wall or the ionic strength of the electrolyte solution adjusts the screening length of the EDL and can hence be used to manipulate the velocity of EOF in the nanopore channel. ${ }^{119}$ 
Table 1 Comparison of the main benefits and characteristics of different methods for coating nanopore walls

\begin{tabular}{|c|c|c|c|c|c|c|c|c|}
\hline \multirow[b]{2}{*}{ Method } & \multicolumn{5}{|c|}{ Application } & \multicolumn{3}{|c|}{ Characteristics } \\
\hline & $\begin{array}{l}\text { Reduce } \\
\text { non-specific } \\
\text { interactions }\end{array}$ & $\begin{array}{l}\text { Manipulate } \\
\text { surface } \\
\text { charges }\end{array}$ & $\begin{array}{l}\text { Engineer } \\
\text { specific } \\
\text { interactions }\end{array}$ & $\begin{array}{l}\text { Change } \\
\text { pore } \\
\text { diameter }\end{array}$ & $\begin{array}{l}\text { Reduce } \\
\text { noise }\end{array}$ & $\begin{array}{l}\text { Ease of } \\
\text { coating }\end{array}$ & $\begin{array}{l}\text { Stability } \\
\text { of } \\
\text { coating }\end{array}$ & $\begin{array}{l}\text { Specialized } \\
\text { equipment }\end{array}$ \\
\hline $\begin{array}{l}\text { Depositions from the vapor } \\
\text { phase }^{82,130,140-154}\end{array}$ & • & + & • & ++ & + & ++ & ++ & Yes \\
\hline Surfactants ${ }^{128,155,156}$ & + & + & - & - & • & ++ & - & No \\
\hline $\begin{array}{l}\text { Other physisorbed surface } \\
\text { modification }^{157-160}\end{array}$ & + & + & + & • & • & ++ & - & No \\
\hline Layer-by-layer self assembly ${ }^{161-170}$ & + & ++ & + & ++ & • & - & + & No \\
\hline Silanization ${ }^{129,171-191}$ & + & + & ++ & + & • & + & + & No \\
\hline $\begin{array}{l}\text { Self-assembled monolayers of thiols on } \\
\text { gold }^{188,192-209}\end{array}$ & + & + & ++ & + & • & + & + & Yes $^{a}$ \\
\hline $\begin{array}{l}\text { Other covalent surface } \\
\text { modifications }{ }^{123,127,210-254}\end{array}$ & + & + & ++ & + & • & + & + & No \\
\hline Fluid lipid coatings $s^{27,107,114,255-261}$ & ++ & ++ & ++ & + & - & - & • & No \\
\hline
\end{tabular}

Coatings which provide a better than average positive outcome are marked with $(++)$, coatings which provide a positive influence on nanopore sensing are marked with $(+)$, those with a neutral influence are marked with $(\bullet)$, and coatings that may incur a negative effect with regard to a certain property are marked with $(-){ }^{a}$ For a self-assembled monolayer of high quality involving a gold surface with the application of thiols, a fresh, unoxidized layer of gold is necessary, typically requiring a set up for sputtering or otherwise depositing thin films of gold.

To address problems such as limited stability of synthetic nanopores by slow "etching" in electrolyte solutions ${ }^{131,132}$ or non-specific interaction of analytes with pore walls of synthetic nanopores, various coating methods have been developed (Fig. 2). These methods range from metal oxide deposition to self-assembled monolayers of thiols on gold (Table 1) and have been discussed previously for use in nanopore experiments in several excellent review articles. ${ }^{133-139}$ This review provides an update as well as a comprehensive exploration of the current status of the use of surface coatings in the nanopore field. With this goal in mind, Table 1 presents an overview of the eight most common coating methods together with their suitability for various applications. Following the organization in this table, this review discusses these coatings as well as their benefits and limitations for the analysis of single macromolecules and particles. While the primary motivation and rationale for nanopore coatings is often to avoid adhesion to the pore wall, once applied, these coatings provide additional advantages, which we will discuss throughout this review.

\section{Types of surface coatings for synthetic nanopores}

\section{Depositions of coatings from the gas phase}

Vapor depositions by atomic layer deposition (ALD) ${ }^{262}$ and chemical vapor deposition (CVD) ${ }^{263}$ allow for the application of material in a well-controlled manner. ${ }^{142}$ The precision, in terms of layer thickness, especially of ALD, which cycles through the deposition of individual single-molecule layers, makes gas-phase depositions an attractive technique for coating nanopore walls. ${ }^{264}$ Alternatively, electron beaminduced deposition (EBID) is a technique for spatially localized deposition that involves physisorption of precursor molecules on the surface followed by deposition mediated by electrons. $^{265,266}$ Potential benefits of depositions on membranes containing a nanopore, besides the obvious change in pore size and shape, ${ }^{140,142,143,146,147,150,151,154}$ include reduction of recording noise, ${ }^{142,149}$ modification of surface properties such as charge or hydrophobicity, ${ }^{130,140,142,147,148}$ control of current rectification, ${ }^{152}$ and manipulation of surface interactions with analytes of interest or with other molecules in a sample. ${ }^{141}$ While depositions of coatings from the gas phase make it possible to reduce the pore diameter, the same process leads to a concomitant, and often undesired increase in nanopore length. Long pores, on the one hand, increase the dwell times of resistive pulses, thereby improving the time resolution; on the other hand, long nanopores have an increased sensing volume and thereby result in a decreased signal to noise ratio compared to shorter pores with the same diameter.

Due to the limited accessibility to recessed nanoscale features, depositions of a continuous film can be difficult to achieve inside nanopores. Elam et al. explored this limitation on pores with high aspect ratios (length/diameter up to 5000) by assessing the uniformity of the coatings at various locations in the pores. ${ }^{144}$ These authors utilized Monte Carlo simulations to predict the necessary exposure times in a general form that could be applied to any porous substrate. ${ }^{144,145}$ In order to further increase the quality of depositions in nanopores Fan et al. developed a dual-stage ALD process. This process led to coatings with high levels of homogeneity and conformity within the pores. ${ }^{153}$

Chen et al. demonstrated that controlled deposition of $\mathrm{Al}_{2} \mathrm{O}_{3}$ by ALD is a potential strategy to reduce $1 / \mathrm{f}$ noise, control the diameter, and neutralize the surface charge of nanopores prepared by ion beam sculpting in silicon nitride membranes. ${ }^{142}$ The authors showed that this coating increased the throughput of DNA translocations through the pore compared to a pore in uncoated $\operatorname{SiN}_{x}$ membranes (Fig. 3). They attributed low throughput before deposition to a variable surface charge distribution 


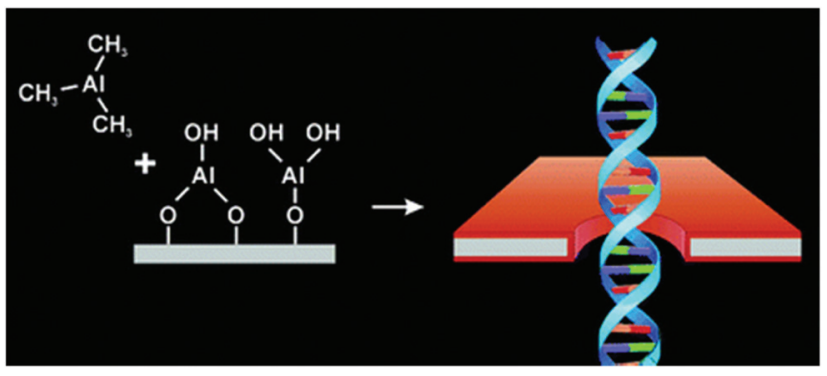

Fig. 3 Representation of the deposition of $\mathrm{Al}_{2} \mathrm{O}_{3}$ on a solid-state chip with a nanopore as an example of a coating prepared by ALD. The coating is shown in red. This $\mathrm{Al}_{2} \mathrm{O}_{3}$ coating allowed Chen et al. to analyze DNA strands without clogging. ${ }^{142}$ Reprinted with permission from ref. 142. Copyright 2004 American Chemical Society.

within the nanopore and hypothesized that the uniform surface properties after ALD coating enabled DNA analysis without clogging and long-lived or permanent blockages. ${ }^{142}$

In an effort to discriminate between single- and doublestranded DNA, Thangaraj et al. performed ALD of $\mathrm{Al}_{2} \mathrm{O}_{3}$ on track-etched nanopores in poly(ethylene terephthalate) (PET) films to reduce the surface charge as well as to control the shape and size of these pores. ${ }^{130}$ Specifically, the deposition reduced the diameter by $\sim 25 \%$ and reduced current fluctuations resulting from free polymer chains on the surface after the track-etching process. The resulting change in pore diameter and increase in aspect ratio, lowered the strength of the electric field and prolonged dwell-time in the pore, enabling the detection of single-stranded DNA (ssDNA) and doublestranded DNA (dsDNA). ${ }^{130}$

In order to reduce the diameter of nanopores, Kox et al. used EBID for applying a coating of a hydrocarbon compound. ${ }^{146}$ The deposition shrunk the nanopore size from around $100 \mathrm{~nm}$ to a diameter of $20 \mathrm{~nm}$ and the resulting elimination of ICR suggested that the shape of the pore changed from conical to symmetric. In addition, using a $\mathrm{SiO}_{2}$ precursor in EBID led to a chemically stable and constant surface charge, facilitating the detection of biological macromolecules. ${ }^{146,147}$

One important aspect of deposition techniques on membranes containing nanopores is that they can increase the stability of the membranes, and in particular, of the pore diameter against slow etching in electrolyte solution during recordings. The long-term stability of the nanopore diameter is essential for quantitative and reproducible experiments, since a small change in nanopore diameter can induce a relatively large difference in the sensing volume, the resistance and the thermal noise of nanopores. During nanopore recordings, pores are immersed in an electrolyte solution with an applied potential difference and are often cleaned aggressively by a hot solution of concentrated sulfuric acid with hydrogen peroxide (so called Piranha solution) or by an $\mathrm{O}_{2}$ plasma between experiments. While $\mathrm{SiN}_{x}$ and $\mathrm{SiO}_{2}$ are considered chemically and physically robust materials, there is nonetheless a problem with slow etching on the nanometer scale. ${ }^{267}$ Specifically, $\mathrm{SiO}_{2}$ on the nanopore walls, which originates either from membranes

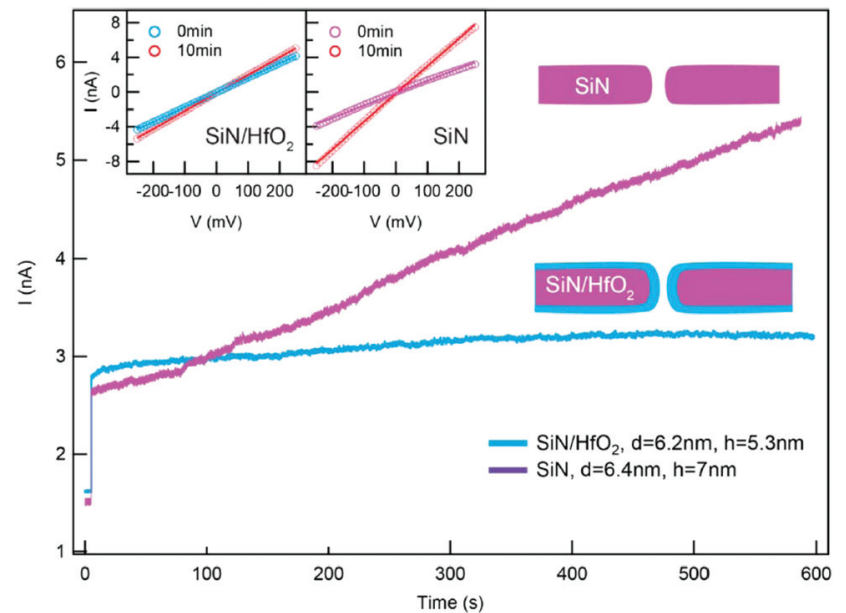

Fig. 4 Coating a nanopore in a $\mathrm{SiN}_{x}$ membrane with a layer of $\mathrm{HfO}_{2}$ effectively inhibited the growth of the nanopore diameter. ${ }^{82} \mathrm{Graph}$ showing a time-dependent recording of baseline current through an uncoated nanopore in a $\mathrm{SiN}_{x}$ membrane (purple) and through a nanopore coated with $\mathrm{HfO}_{2}$ (blue) while a voltage of $100 \mathrm{mV}$ was applied and while the membrane was simultaneously illuminated by a laser $(532 \mathrm{~nm})$. Insets: Current versus voltage curves showing the difference in resistance of two nanopores before and after measurements that lasted for $10 \mathrm{~min}$. Reprinted with permission from ref. 82. Copyright 2018 American Chemical Society.

composed entirely of $\mathrm{SiO}_{2}$ or from oxidation of the surface of $\operatorname{SiN}_{x}$ membranes, hydrolyzes slowly to silicic acid and dissolves in the electrolyte solution during recordings. ${ }^{131,268}$

The etch rate of $\mathrm{SiN}_{x}$ or $\mathrm{SiO}_{2}$ during nanopore experiments varies as a function of temperature, $\mathrm{pH}$, salt concentration, applied voltage, nanopore shape and nanopore fabrication methods ${ }^{132,267,269,270}$ and can sometimes be sufficiently fast to lead to a noticeable increase in conductivity through the growing pore during the experiment. The resulting uncertainty in pore diameter, shape, volume, and electric field inside the pore leads to uncertainty in quantitative resistive pulse experiments that aim to characterize translocating particles or molecules.

One promising coating that can be applied by gas phase deposition is hafnium oxide $\left(\mathrm{HfO}_{2}\right)$. This coating has shown high chemical stability during extended nanopore experiments. ${ }^{71,88}$ For instance, by depositing a thin layer of $\mathrm{HfO}_{2}$ using ALD on the walls of a nanopore formed in a $\mathrm{SiN}_{x}$ membrane, Yamazaki et al. have effectively inhibited $\operatorname{SiN}_{x}$ dissolution in a photothermal etching environment (Fig. 4). ${ }^{82}$ Coating nanopores with a protective self-assembled monolayer (SAM) has also been shown to prevent nanopores from slow etching in aqueous electrolyte solution and enabled measurements for several days. ${ }^{172,271}$ Nonetheless, slow etching of nanopores leading to increasing pore diameters continues to be one of the major challenges in recordings with solid-state nanopores, especially when very thin insulating membranes $(<30 \mathrm{~nm})$ are required.

\section{Surfactant-based nanopore coatings}

Surfactants (surface-active agents) can adsorb on surfaces and alter the surface chemistry of that surface. ${ }^{128,272-274}$ These 

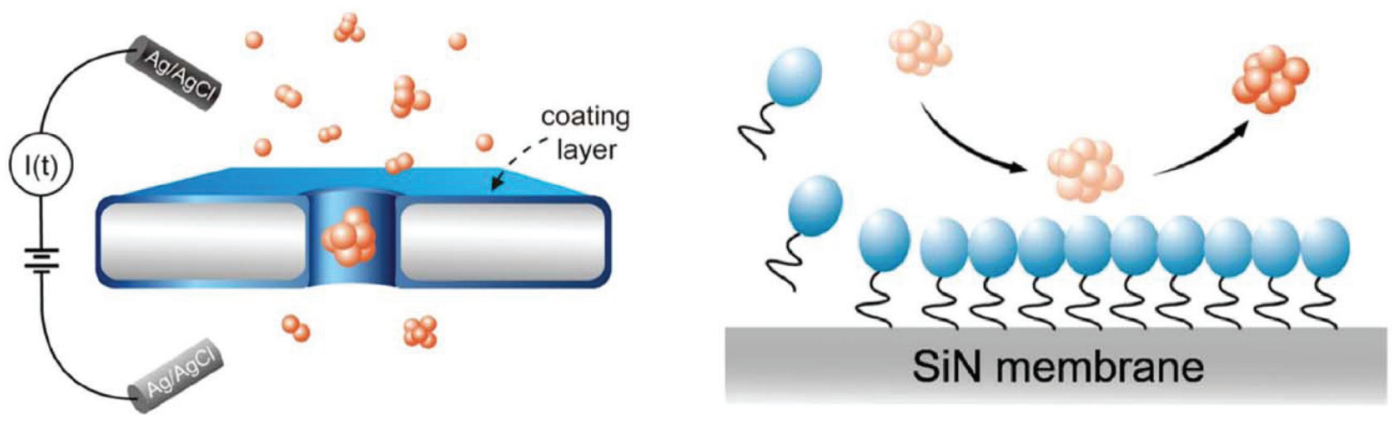

Fig. 5 Cartoon representation of the putative effect of Tween 20 (shown in blue) on non-specific adsorption of proteins to the pore wall. ${ }^{155}$ The circles represent the hydrophilic moiety while the tails represent the hydrophobic moiety of the surfactant molecules. Figure from ref. 155.

amphiphilic agents consist of both hydrophobic and hydrophilic residues, allowing, in some cases, for their unaided adhesion to surfaces. ${ }^{274}$ Surfactants typically lower surface tension and may perform additional functions such as foaming, inhibiting corrosion, and killing bacteria. ${ }^{272,273}$ Nanopore coatings with surfactants such as Tween 20 and cetyl trimethyl ammonium bromide (CTAB) are primarily employed to reduce interactions of biomolecules with the pore wall; ${ }^{155,156}$ they can, however, also provide the ability to alter surface charge density and therefore current rectification. ${ }^{128}$

$\mathrm{Hu}$ et al. showed that the commercially-available surfactant Tween 20 prevented irreversible clogging of nanopores as a result of minimized protein adsorption to the pore wall; ${ }^{155}$ Fig. 5 illustrates the proposed mode of action. ${ }^{155}$ Specifically, the authors suggested that Tween 20 application to silicon nitride nanopores rendered the surface more hydrophilic (as confirmed by contact angle experiments), minimizing adhesion of the protein alpha-synuclein that is implicated in Parkinson's disease. ${ }^{275}$ This modification allowed for the identification of four types of alpha-synuclein oligomers ${ }^{155}$ as well as the differentiation between ssDNA and dsDNA. ${ }^{156}$

Xie et al. tested CTAB for generating a coating that inverted the negative surface charge of track-etched nanopores in PET foils to a surface with a positive charge. ${ }^{128}$ Through the adjustment of the СТАВ concentration in the solution used for recording, the authors changed the surface charge from $-9 \mathrm{mC} \mathrm{m}^{-2}$ to $+8 \mathrm{mC} \mathrm{m}^{-2}$, and thereby tuned the properties of current rectification. ${ }^{128}$

\section{Other coating methods by physisorption}

The physisorption of molecules to generate coatings on a membrane with a nanopore constitutes one of the most straightforward to use surface modifications. To this end, one of the most commonly employed approaches is adsorption of positively-charged poly-L-lysine (PLL) onto negatively charged surfaces. These PLL coatings were reported to block the adhesion of molecules on the pore wall, ${ }^{157}$ to allow for the manipulation of surface charges, ${ }^{157,159}$ as well as to engineer specific interactions. One example of a specific interaction was that of mycotoxins ${ }^{160}$ and the protease thrombin ${ }^{158}$ using a cross-linker that attached to the amino groups in PLL and to cysteine residues on antibodies specific to the molecule of interest.

In the case of nanopores in graphene, Schneider et al. showed that the non-covalent self-assembly of a monolayer of amphiphilic molecules, which exposed hydrophilic end groups blocked hydrophobic interactions between DNA and the graphene walls of the pore. ${ }^{157}$ This coating was composed of a molecule that combined a hydrophobic aminopyrene residue with a hydrophilic tetrameric ethylene glycol moiety. The pyrene moiety putatively interacted with the graphene and the ethylene glycol protruded out from the pore wall, rendering the surface hydrophilic. This modification enabled the detection of dsDNA and ssDNA with improved reproducibility, ${ }^{157}$ illustrating the potential of coated nanopores in graphene sheets.

Umehara et al. examined the effect of PLL coatings on the mobility of ions within nanopipette electrodes. ${ }^{159}$ Uncoated pipettes exhibited ICR as expected from their conical shape, while PLL-coated pipettes displayed increased rectification at the opposite polarity compared to the uncoated pipettes. ${ }^{119}$ This change occurred as the positively charged PLL coating inverted the polarity of the negative surface charge of the bare glass wall of the nanopipette.

Coatings made from PLL were also used in a so-called signal transduction by ion "nanogating" (STING) sensor using a quartz nanopipette. ${ }^{158,160}$ Actis et al. introduced this concept for the detection of the mycotoxin HT-2 by taking advantage of immunoglobulin ( $\operatorname{IgG})$ molecules crosslinked to the PLL coating (Fig. 6). ${ }^{160}$ Immobilization of thrombin aptamers to a layer of PLL and polyacrylic acid (PAA) allowed for the detection of thrombin using the same sensing platform. ${ }^{158}$

\section{Coatings formed using layer-by-layer self assembly}

The coating technique layer-by-layer self-assembly (LBL) employs a cycle of alternating deposition of oppositely charged polyions to create thin films. ${ }^{276-279}$ These depositions typically begin with a positively charged layer to capitalize on the negative charges present on most surfaces, including glass, silicon, and metals. ${ }^{280,281}$ Layer-by-layer self-assembly allows for nanoscale precision when adjusting the diameter of a nanopore since each bilayer usually contributes an increase in thickness of less than $1 \mathrm{~nm}$. While the compositions of the layers and 


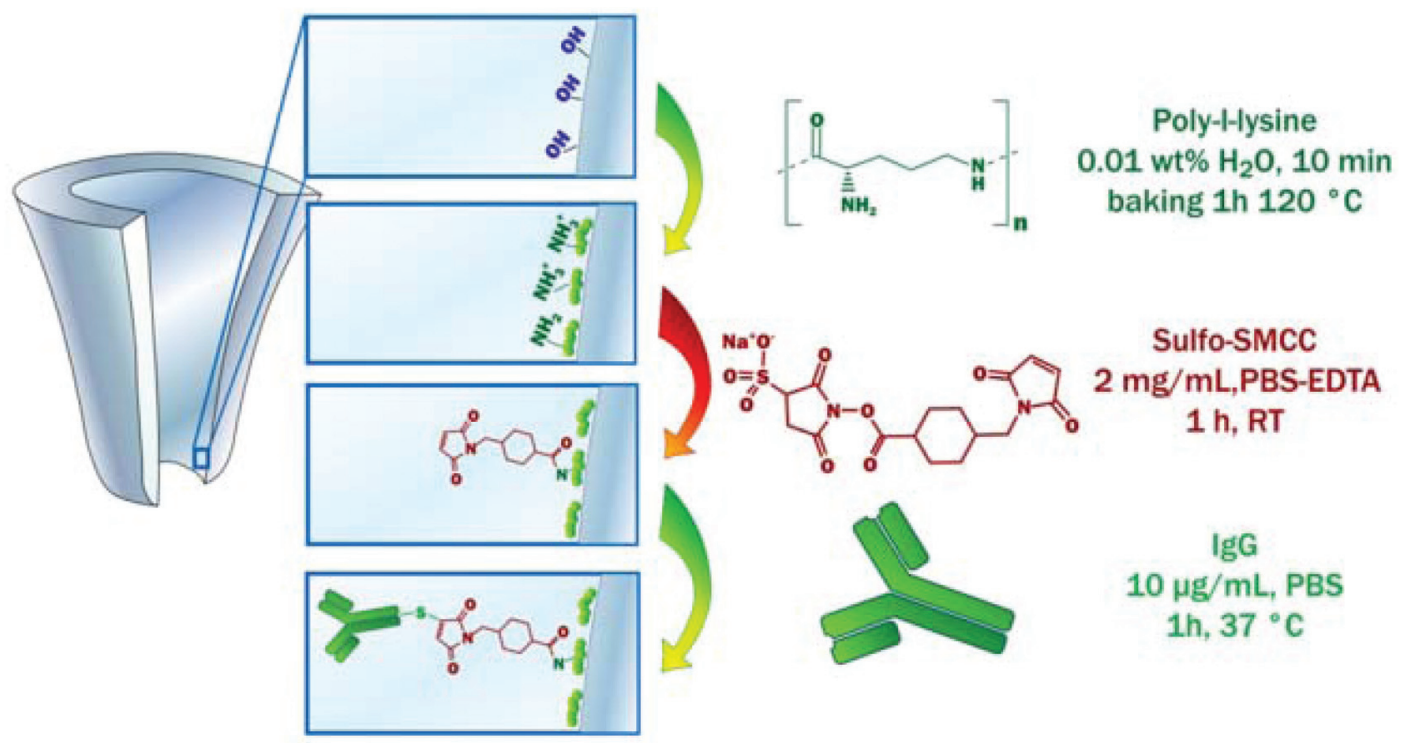

Fig. 6 The functionalization of a quartz nanopipette by the physisorption of PLL and subsequent immobilization of IgG molecules. This coating allowed for the detection of the mycotoxin HT-2, a small toxin that is difficult to detect. ${ }^{160}$ Reprinted from ref. 160 with permission from Elsevier.

the deposition techniques vary, LBL coatings are most commonly used to manipulate nanopore size, ${ }^{164}$ tailor surface chemistry, ${ }^{165-169}$ or allow for the incorporation of other molecules for specific detection of certain analytes. ${ }^{161-163,166,167,170}$

In order to adjust the diameter and surface charge density of a nanopore, Lepoitevin et al. deposited alternating layers of PLL and poly(styrene sulfonate) onto track-etched, conicallyshaped nanopores in PET. ${ }^{167}$ This approach modified the pore's ICR characteristics, while the addition of PLL grafted with poly(ethyleneglycol) ( $N$-hydroxysuccinimide 5-pentanoate) ether 2-(biotinylamino) ethane (NHS-mPEG-biotin) made it possible to attach or recognize biotin-binding proteins. ${ }^{167}$ To design a nanopore that could be gated by the variation of $\mathrm{pH}$ and that responded to differences in ion concentration, Zhao et al. performed LBL with polyethylenimine (PEI) and chondroitin-4-sulfate (ChS) on track-etched pores (Fig. 7). ${ }^{168}$

Blundell et al. used layer-by-layer assembly to functionalize conical nanopores prepared in thin polyurethane membranes. ${ }^{166}$ The coating made it possible to control the ionic conductance through the nanopore by changing the $\mathrm{pH}$ value and ionic strength of the recording electrolyte. ${ }^{166}$ The authors demonstrated that layers composed of PEI and polyacrylic acid-maleic acid (PAAMA) with the incorporation of an aptamer enabled the detection $5 \mathrm{pM}$ concentrations of the cancer biomarker vascular endothelial growth factor (VEGF). ${ }^{166}$

\section{Nanopore coatings by silanization}

Silanization involves the reaction of organosilanes with surface hydroxyl groups, in a process that can be associated with molecular self-assembly. ${ }^{282,283}$ Silanes comprise both organic and inorganic moieties and can form covalent bonds with varying levels of stability ${ }^{282}$ on surfaces of a variety of substrates

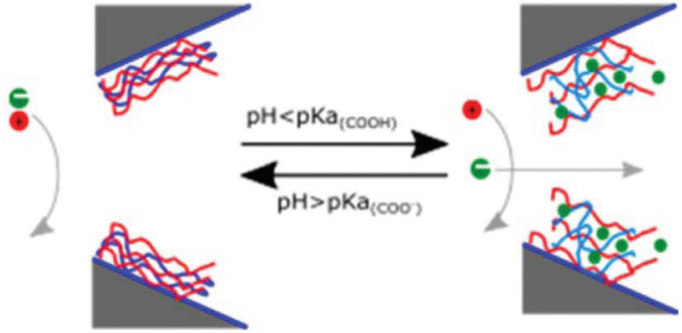

Fig. 7 The mechanism of a nanopore gate formed by layer-by-layer self-assembly of $\mathrm{PEI}$ and $\mathrm{ChS}$ and its response to changes in $\mathrm{pH}$ value of the aqueous recording electrolyte as proposed by Zhao et al. ${ }^{168}$ At low ionic strength, the ionic current through the pore responded to changes in $\mathrm{pH}$ value: at $\mathrm{pH}$ values smaller than 4 , the gate opened for flux of anions, while at $\mathrm{pH}$ values above 4, anion flux was significantly reduced. ${ }^{168}$ Reprinted with permission from ref. 168. Copyright 2017 American Chemical Society.

including quartz, ${ }^{284}$ aluminum oxide, ${ }^{285}$ and iron oxide. ${ }^{286}$ In the absence of polymerization, silanization forms thin coatings with low surface density, which may be used to increase hydrophobicity ${ }^{185,190}$ or to reduce non-specific surface adhesion. ${ }^{283}$ In the context of nanopores, silanization allows for the functionalization of pore walls by enabling the attachment of DNA, ${ }^{173,175,178,183}$ dendrimers, ${ }^{174}$ nucleoporins, ${ }^{176}$ aldehydes, ${ }^{172,177}$ spiropyran moieties, ${ }^{181}$ cysteines, ${ }^{187}$ carboxylic acid, ${ }^{172}$ EDTA, ${ }^{188}$ peptides, ${ }^{189,191}$ and polymer brushes ${ }^{182}$ to chemical groups that are attached to the silane molecule. Apart from the possibility of such attachments, silanization can generate a coating with antifouling properties ${ }^{184}$ and can be used to manipulate ICR $^{185}$ and other charge-based properties, ${ }^{179}$ including the modulation of surface charge by changing the $\mathrm{pH}$ value of the recording electrolyte ${ }^{129,180,186}$ 
and the regulation of transport through the conformational change of ligands in response to light or heat. ${ }^{171}$

Tan et al. performed silanization with 3-aminopropyltriethoxysilane (APTES) on silicon nitride nanopores (which typically have a thin layer of $\mathrm{SiO}_{2}$ on their surface ${ }^{287}$ ) to render the net charge of the pore surface positive due to protonated terminal amine groups. ${ }^{179}$ The authors chose a functionalization with amine groups to reduce EOF-related drag as well as to attract negatively charged nanoparticles to the pore entrance for detection of translocation events at increased frequency. ${ }^{179}$

Wanunu and Meller created nanopores that responded to changes in $\mathrm{pH}$ or to the presence of certain proteins by attaching carboxylic acid or aldehyde groups to silane coatings on the pore. To this end, they coated the pores with a variety of organosilane reagents containing epoxy, methoxyethylene glycol and amine moieties before attaching molecules that either displayed carboxylic acid groups or displayed aldehyde groups upon conjugation. ${ }^{172}$ Fig. 8 shows the pH sensitivity exhibited by such a system. The coatings were formed in two ways: through (i) immersion of nanopore chips in the silane solution and (ii) voltage-driven mass transport to promote uniform coating of small pores (5 $\mathrm{nm}$ in diameter) without clogging. ${ }^{172}$ To understand the $\mathrm{pH}$ dependence of selective transport of certain ions through nanopores, Wang et al. applied two different alkylsilanes to conical glass nanopores with a platinum disk electrode embedded at the bottom of the pore. ${ }^{180}$ Specifically, a monolayer terminated in $-\mathrm{CN}$ groups modified the exterior surface while an amine-terminated monolayer modified the interior surface of the pore. Protonation and deprotonation of the $-\mathrm{NH}_{2}$ groups affected the flux of charged species. ${ }^{180}$

To allow selective detection and sequencing of short strands of DNA through specific interactions with a binding partner in a nanopore, Iqbal et al. attached a hairpin loop of DNA via a silane layer (APTES) and a homo-bifunctional crosslinker (1,4-phenylene diisothiocyanate). The silanization of these pores also decreased their effective diameter to increase the amplitude of resistive pulses generated by DNA translocation. ${ }^{175}$ Also in the pursuit of DNA sequencing, Anderson et al. silanized solid-state nanopores to form a 'polymeric cushion' between the DNA and the pore walls. ${ }^{129}$ This cushion, composed of APTMS, prevented DNA from sticking to the nanopore walls and slowed its translocation time through the modification of the surface charge. By varying the solution's $\mathrm{pH}$, the authors were able to vary the translocation times of unfolded DNA. ${ }^{129}$

Nilsson et al. functionalized nanopores in a silicon nitride membrane that had been prepared by focused-ion-beam drilling through a three step process. ${ }^{178}$ They first grew a silicon oxide ring locally through ion-beam-assisted deposition. The oxide surface then reacted with mercaptopropyltrimethoxysilane to anchor thiol-terminated linkers. Finally, acrylamide-terminated ssDNA strands reacted with the thiol groups on the linkers, enabling detection of specific biological materials (anything from viruses to cells) through reactions with these DNA probes. ${ }^{178}$ In another example, Ding et al. immobilized aptamers on the silanized wall of nanopores in order to render glass nanopores specific for detection of proteins. ${ }^{173}$ Interaction of immunoglobulin $\mathrm{E}$ (IgE) and ricin molecules with aptamers in the narrow sensing zone of the pore enabled their detection. ${ }^{173}$

Tang et al. coated solid-state nanopores in silicon nitride membranes with polyethylene glycol $\left(\mathrm{PEG}_{200}\right)$ to improve the detection of ssDNA and dsDNA. ${ }^{190}$ This PEG layer lowered hydrophilicity, ${ }^{190}$ 1/f noise, and the $\mathrm{pH}$-dependent surface charge.

\section{Coatings from self-assembled monolayers of thiols on gold}

Self-assembled monolayers ${ }^{288}$ are a well-studied and commonly employed approach to modify or functionalize surfaces for a variety of applications ranging from prevention of corrosion, formation of protein-repellant surfaces ${ }^{289}$ to employ-
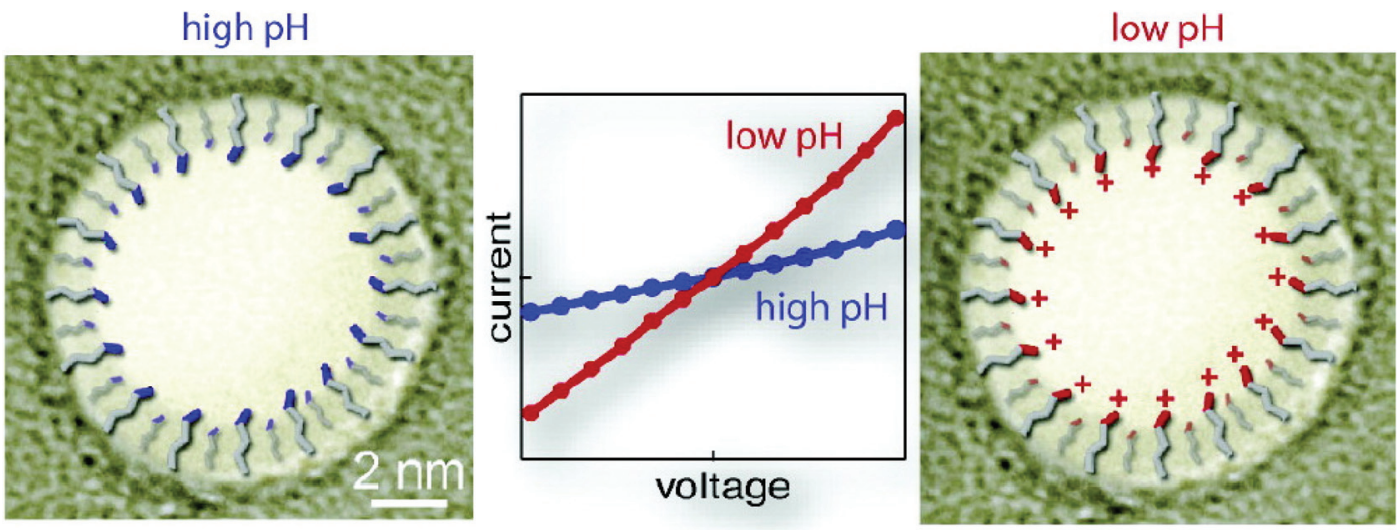

Fig. 8 Effect of $\mathrm{pH}$-dependent surface charge of nanopores coated with a silane with protonatable end groups proposed by Wanunu and Meller. ${ }^{172}$ Uncoated pores did not show the same $\mathrm{pH}$-dependence as those coated with 3-(aminopropyl)trimethoxysilane (APTMS). At relatively low ionic strength $(0.14 \mathrm{M} \mathrm{KCl})$, the conductance through coated pores varied with the $\mathrm{pH}$ value in the recording electrolyte, while uncoated pores displayed no sensitivity to $\mathrm{pH}$ at either low ionic strength or at $1.0 \mathrm{M} \mathrm{KCl} .{ }^{172}$ Reprinted with permission from ref. 172 . Copyright 2007 American Chemical Society. 
ment as active or passive elements in transistors or switches. $^{290,291}$ The SAMs discussed here are composed of molecules with terminal thiol groups that allow for covalent conjugation to a freshly prepared gold layer on the nanopore surface. Apart from gold deposition, SAM preparation does not require specialized equipment, the monolayers can form over large surfaces and they can provide surface groups that repel molecules, interact with, or covalently link to molecules of interest. ${ }^{288,292}$ In the context of nanopore sensing, SAMs are predominantly used for sensing specific analytes, ${ }^{193,201,203,204}$ minimizing non-specific interactions, ${ }^{188,197,200,202,208}$ manipulating surface charge, ${ }^{192,194,196-198}$ and adding functionality such as gating of the pore, ${ }^{192,205,206}$ preferential transport, ${ }^{194,196-199}$ or enhancing the signal of plasmonic nanopores. ${ }^{207,209}$

Charles R. Martin's group was among the first to take advantage of SAMs in nanopores by chemisorbing thiols to gold surfaces deposited onto track etched nanotubes. ${ }^{195}$ The same group has since explored other modifications involving SAMs. ${ }^{198}$ For example, they varied the hydrophobicity of gold nanotubules by choice of the $\mathrm{R}$ group in the alkane thiol molecules that they chemisorbed to the tubule walls in order to explore its influence on transport of molecules with varying hydrophobicity. ${ }^{196}$ This research showed that membranes made from functionalized gold nanotubules separated hydrophobic molecules from hydrophilic species. In another study, Lee and Martin chemisorbed cysteine to gold nanotubule membranes to introduce $\mathrm{pH}$-switchable selectivity for iontransport. ${ }^{197}$ At a low pH (when the cysteine's carboxyl and amino groups were protonated), the membranes allowed the passage of anions and rejected cations (Fig. 9). The opposite was true at a high $\mathrm{pH}$. At the isoelectric point of cysteine $(\mathrm{pH}=$ 6.0), no transport selectivity was observed.

In another example of engineering specific interactions on the pore surface, He et al. formed a gold film on glass nanopores with $\sim 30 \mathrm{~nm}$ diameters and decorated the film by selfassembly of 2-thiouracil (2-TU). ${ }^{193}$ Hydrogen bonding between the amide moieties of uric acid and the 2-TU surface molecules allowed for the specific detection of uric acid, a biomarker used in the diagnosis of diseases like gout, arthritis and renal disease. ${ }^{293}$ As the authors increased the concentration of uric acid in the recording buffer, the ionic current increased to a stable value, indicating the binding of uric acid to the SAM coating. ${ }^{193}$

A SAM of nitrilotriacetic acid (NTA) groups on the goldcoated walls of a nanopore enabled specific detection of Histagged proteins. ${ }^{204}$ This SAM also shrunk the diameter by $\sim 6 \mathrm{~nm}$ and prevented nonspecific interactions between proteins and pore walls. Wei et al. demonstrated the specificity for binding of His-tagged proteins with control experiments using imidazole as a competitive binder (Fig. 10). ${ }^{204}$ In another example of using nanopores in the context of protein biophysics, Jovanovic-Talisman et al. sought inspiration from the nuclear pore complex (NPC) and rendered the walls of nanopores in a polycarbonate film specific for transport of proteins of interest. ${ }^{203}$ To recreate the NPC, the authors applied a gold

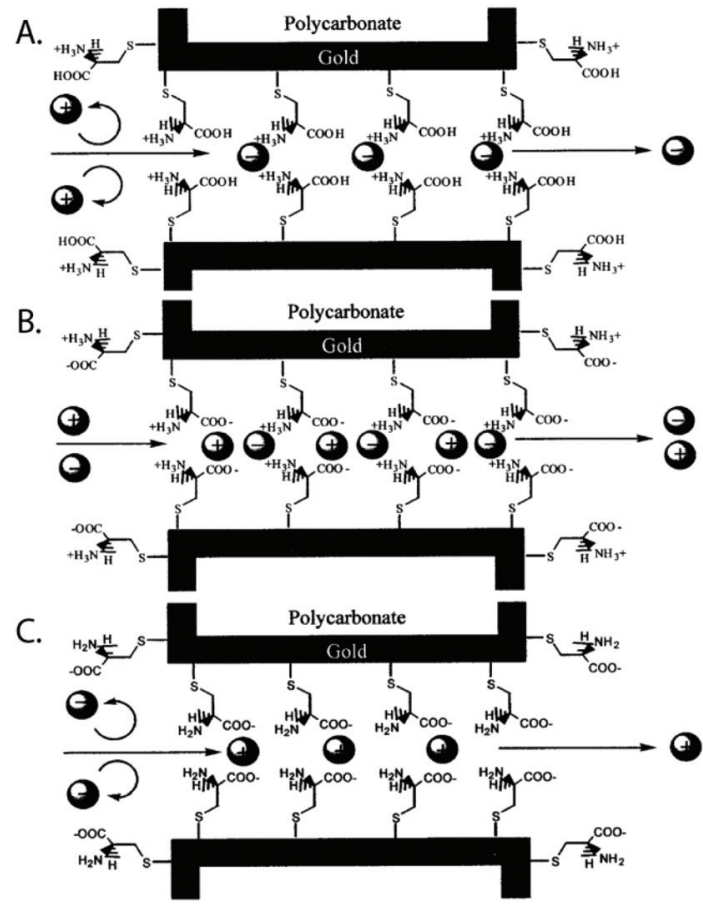

Fig. 9 A representation of the three protonation states of cysteine chemisorbed to a gold-coated nanopore wall as proposed by Lee and Martin. ${ }^{197}$ A. At a low $\mathrm{pH}$, the cysteines were protonated resulting in a state that permitted transport of anions and rejected cations. B. Close to the isoelectric point of cysteine, a pH of 6 , no significant selectivity for cations or anions was observed. C. At a high $\mathrm{pH}$, the cysteines were deprotonated resulting in a state that permitted transport of cations and rejected anions. ${ }^{197}$ Reprinted with permission from ref. 197. Copyright 2001 American Chemical Society.

layer on synthetic nanopores, attached FG-nucleoporins through a C-terminal cysteine, and attached small PEG-thiol molecules to passivate remaining areas of exposed gold. This artificial NPC effectively behaved as a filter, allowing the preferred passage of cargo in complex with transport factors specified to bind to multiple repeats of Phy-Gly (FG) motifs in the FG-nucleoporins. ${ }^{203}$

Sexton et al. attached PEG-thiol molecules to a gold layer prepared on the surface of track etched conical nanopores in PET membranes for the prevention of protein adsorption. ${ }^{202}$ With these PEG-functionalized nanopores, the authors distinguished translocation of bovine serum albumin (BSA) in complex with anti-BSA Fab fragments from translocations of BSA alone. ${ }^{202}$ This work followed a study from the same group, which exploited the advantages provided by a PEG-thiol coating to separate proteins as a function of their size by adjusting the size of the nanotubules. ${ }^{199}$

Siwy et al. deposited gold on conical nanopores in PET membranes to form gold nanotubes and functionalized the tubes with three different molecules for molecular-recognition. ${ }^{201}$ Specifically, the authors exploited the strong interaction between biotin and streptavidin, protein $\mathrm{G}$ and IgG, and ricin and its antibody to increase the selectivity and sensitivity of the pores for these three analytes. The result was a simple 
A.

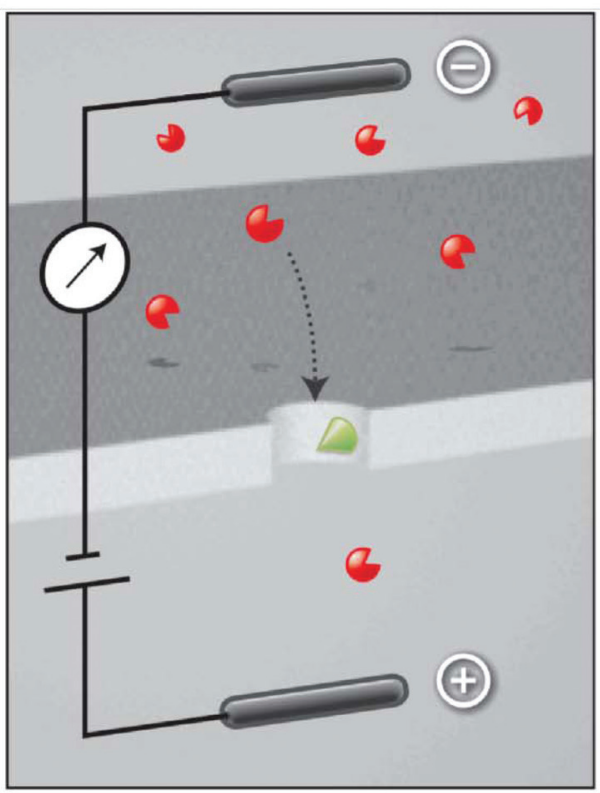

B.

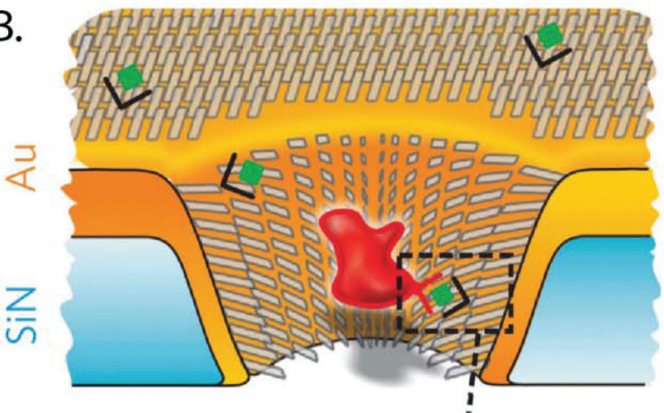

C.

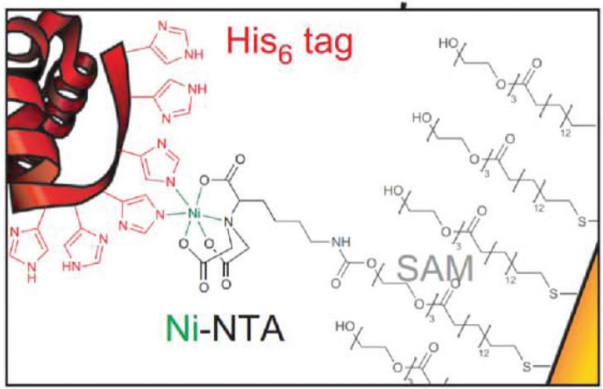

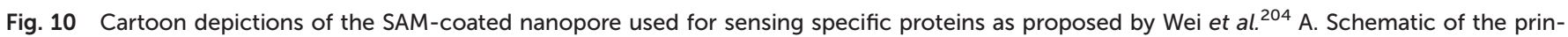

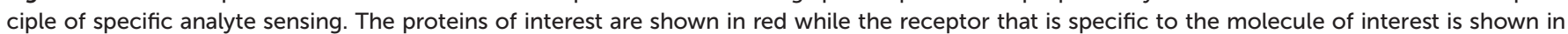

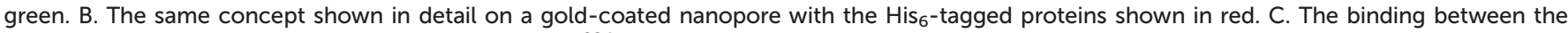
His-tagged protein and the SAM coating the nanopore. ${ }^{204}$ Reprinted with permission from ref. 204. Copyright 2012 Springer Nature.

Boolean sensor: binding of the molecule of interest near the nanotube orifice led to a current blockage indicating the presence of the molecule. ${ }^{200,201}$

\section{Other covalent surface modifications}

Nanopore surfaces that expose carboxyl groups are often coated by reaction with carbodiimide moieties for coupling molecules of interest. ${ }^{123,127,212-234,237,238,240-247,254}$ This technique works well on the walls of nanopores in polymer films and is robust and versatile, particularly for imparting specificity for detection of specific DNA strands or other biomolecules. ${ }^{217,218,223,224,227,229,232,244,254}$ The same coupling chemistry has been employed to engineer nanopore systems that can be gated ${ }^{210,212,214-216,219,221,235,238,241,246}$ or to generate nanopore diodes. ${ }^{123,219,232,233,239,242}$ Other covalent modification techniques include spin-coating, ${ }^{252}$ hydrosilylation, ${ }^{253}$ plasma-induced graft polymerization ${ }^{210,211}$ and crosslinking other functional groups such as DNA strands, ${ }^{235,236}$ spiropyrans, ${ }^{239}$ or 4 -carboxyl benzyl phosphonic acid ${ }^{248}$ directly to the surface of the pore wall.

To create a $\mathrm{pH}^{-}$and voltage-sensitive mesh within a nanopore, Buchsbaum et al. attached ssDNA probes to the walls of conical pores in a PET film by reacting the amino groups at the 5 ' end of DNA oligomers with the carboxyl groups on the pore wall. ${ }^{212}$ At a low $\mathrm{pH}$, the DNA strands bound to each other through electrostatic interactions (AC-rich strands became protonated and GT-rich strands did not) and increased the resistance through the pore by approximately 60-fold to several tens of gigaohms. At a neutral $\mathrm{pH}$, switching the polarity of the applied voltage controlled the 'gating' mecha- nism: with the application of a negative potential, the authors proposed that the DNA strands preferentially deflected towards the smaller pore opening, causing a partial blockade, while the opposite polarity presumably caused the end of the DNA strands to move preferentially towards the larger opening, "opening" the pore. ${ }^{212}$ This research group also created diodes and transistors from a nanopore in a polymer film. ${ }^{123,241,242}$ To realize a similar strategy for gating the ion flux through a nanopore, Lepoitevin et al. performed ALD of thin $\mathrm{Al}_{2} \mathrm{O}_{3} / \mathrm{ZnO}$ films on track-etched nanopores in a PET film followed by exposure of the nanopore chip to $N$-[3-(trimethoxysilyl)propyl] ethylenediamine (AEAPTMS) vapor. This treatment generated $-\mathrm{NH}_{2}$ groups on the surface. Finally, they linked biotin-PEG molecules to the pore walls through AEAPTMS grafting to the surface $-\mathrm{NH}_{2}$ groups. ${ }^{213,214}$ Changes in $\mathrm{pH}$ resulted in changes in the resistance of the nanopore or, after functionalization of the biotin-PEG layer with the proteins avidin or streptavidin, this system detected biotinylated IgG, and biotinylated BSA. ${ }^{213}$ Finally, the same group applied a PEG layer on the walls of nanopores in a PET film through linking to carboxylate groups on the pore surface to enable the detection of amyloids without clogging $^{247}$ or they attached PEG-spiropyrans to the same pores to generate a light- and $\mathrm{pH}$-responsive nanopore. ${ }^{246}$

Inspired by biological ion channels, Brunsen et al. functionalized a mesoporous thin film of silica with polymer brushes composed of poly(methacryloyl ethylene phosphate) (PMEP) to modulate ion transport by changing $\mathrm{pH}$. The polymer brushes either interacted with or repelled each other depending on the pH. ${ }^{251}$ Yameen et al. explored this concept on conical nanopores by influencing ion flow based on thermally-controlled 


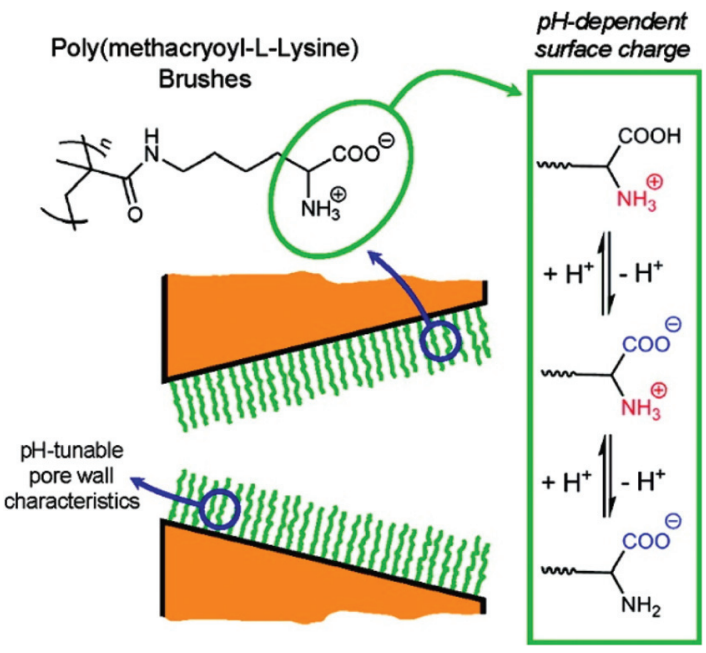

Fig. 11 Cartoon depiction of nanopores with a coating of polymer brushes whose ion transport properties could be tuned by changes in $\mathrm{pH}^{249}$ Reprinted with permission from ref. 249. Copyright 2009 American Chemical Society.

gating (Fig. 11). ${ }^{215,216,249,250}$ Briefly, at room temperature the polymer brushes were in a swollen state while an increase in temperature past the critical solubility level caused the brushes to switch to the collapsed state, increasing the nanopore's effective diameter.

Ali et al. constructed a device for the detection of SsDNA oligonucleotides through carbodiimide-mediated coupling of specific peptide nucleic acid (PNA) probes to the surface of track-etched nanochannels in polyimide membranes. ${ }^{217}$ These uncharged PNA probes also decreased the pore's ICR by about $70 \%$ compared to the ICR before modification. ${ }^{217}$ Using the same technique to immobilize aptamers designed to selectively bind the enzyme lysozyme, this group locally anchored lysozyme onto the pore surface to accumulate charge and increase ICR. Lysozyme has a high isoelectric point of $11.4,{ }^{294}$ therefore the molecules were positively charged under the experimental conditions. ${ }^{218}$ Kececi et al. modified PET membranes by reacting surface-exposed $-\mathrm{COO}^{-}$groups with ethanolamine through (1-ethyl-3-[3-dimethylaminopropyl] carbodiimide hydrochloride, EDC) coupling chemistry to reduce surface charge. ${ }^{127}$ The authors used these nanopores to detect short DNA strands and to distinguish between strands of different lengths.

\section{Fluid lipid coatings}

Coatings from fluid layers of lipids are attractive because they solve several of the most common problems in the context of nanopore recordings of proteins and other macromolecules. ${ }^{107,114,295}$ Inspired by the lipid-coated nanopores present in the antennae of silk moths ${ }^{296,297}$ (Fig. 12A), our group demonstrated, for instance, that lipid coatings efficiently prevent or minimize non-specific adsorption of proteins to the pore wall, eliminating clogging. ${ }^{27,80,107,114,258,259}$ In addition, lipid coatings make it possible to imbue the coating with the capability to engage in specific interactions with target analytes by the incorporation of lipid-anchored ligand or receptor molecules. Binding of proteins of interest to these ligands or receptors tethers them to the bilayer (Fig. 12B) but due to the fluid nature of this lipid coating, lipid anchored target proteins can still move and translocate through lipidcoated nanopores. Depending on the strength of the interaction, these lipid anchors can concentrate molecules of interest onto the fluid coating, increasing the sensitivity of detection. ${ }^{107}$ Alternatively, proteins can be cross-linked covalently to lipid anchors ${ }^{27}$ or proteins such as GPI-anchored proteins, which are intrinsically lipidated, can be examined. ${ }^{107}$ Lipid anchors provide the advantage to slow down the speed of translocation of the anchored target molecules by two orders of magnitude as a result of the drag of the anchor in the viscous fluid lipid coating. Finally the zwitterionic nature of
A.

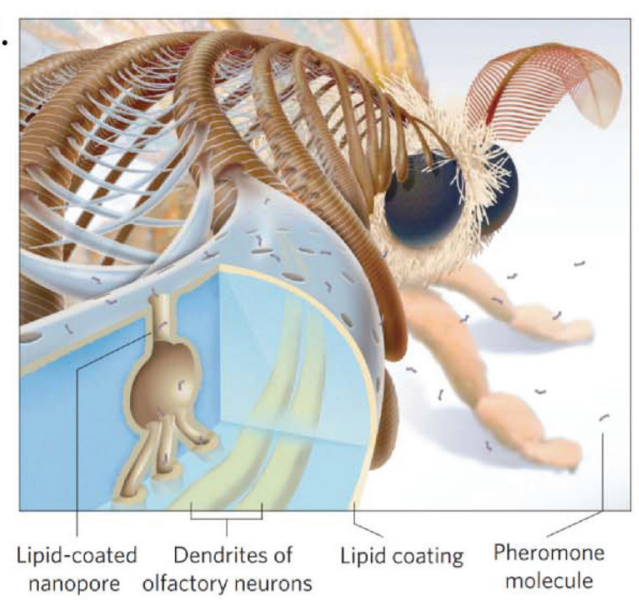

B.

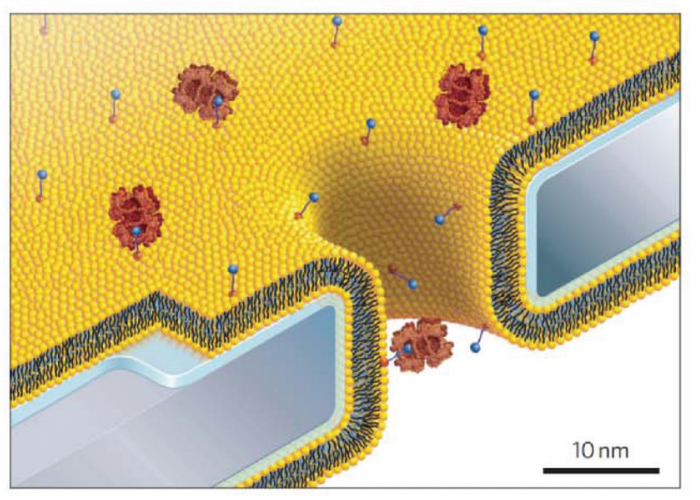

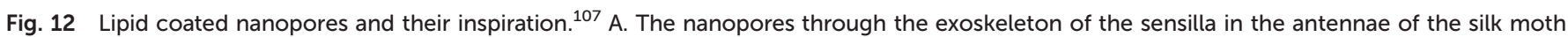

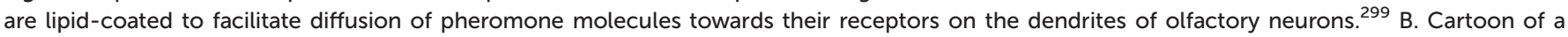

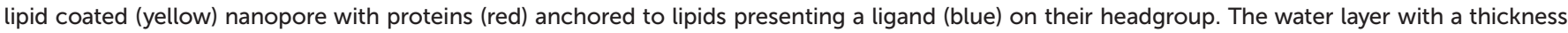
of $\sim 1 \mathrm{~nm}$ between the supported lipid bilayer and the chip surface is indicated in blue. ${ }^{107}$ Figure from ref. 107. 
lipids with phosphatidylcholine head groups in the coating almost completely eliminates electroosmotic flow ${ }^{107,114,255,256}$ and eliminates or minimizes non-specific interactions with many proteins. ${ }^{27}$

Fig. 12 shows a schematic of a nanopore coated with a phospholipid bilayer. In one example, our group took advantage of lipid coatings to investigate the aggregation of amyloid$\beta$ oligomers, which are associated with neurodegenerative diseases such as Alzheimer's disease..$^{259,275}$ Without the fluid lipid coating these experiments typically ended within seconds because amyloid- $\beta$ samples clogged uncoated nanopores in silicon nitride membranes ${ }^{298}$ while lipid coatings enabled recordings for more than $40 \mathrm{~min}$. More recently, we took advantage of the reduced translocation speed of lipidanchored proteins to characterize them on the single molecule level by determining their shape, rotational diffusion coefficient, dipole moment, and charge. ${ }^{27}$ For these applications, the lipid coating is essential because, on the one hand, it slows down the rotation and translocation of lipid-anchored proteins sufficiently to time-resolve their rotational motion in the pore ${ }^{27,295}$ and, on the other hand, the coating provides a non-stick surface that enables translational and rotational motion of the protein without artifacts from non-specific adsorption. $^{295}$ Artifact-free rotation is required to quantify a protein's rotational diffusion coefficient as well as its bias towards certain orientations in the electric field inside the nanopore; it is this bias that we used to estimate the dipole moment of individual proteins. ${ }^{27,295}$ We compared other nanopore coatings such as silanization and surfactant coatings with Tween $20^{295}$ to lipid coatings but in our hands these alternative coatings did not eliminate wall interactions and led to artifacts.

Our group explored a variety of lipid compositions with regard to their benefits in fluid lipid coatings. ${ }^{114}$ To this end, we evaluated the lipid coatings based on four major characteristics: stability of the recorded current baseline, current noise, ability of the coating to slow down the speed of translocation, and ease of preparing a stable nanopore coating. We concluded (Table 2) that the best coatings were either composed of 1-palmitoyl-2-oleoyl-sn-glycero-3-phosphocholine (POPC) with 0 to $20 \mathrm{~mol} \%$ cholesterol or of monolayer-forming lipids inspired from Archaea with 0 to 40 mol\% POPC. These tethered lipids provide the advantage that they result in fluid lipid coatings with approximately 10 -fold increased viscosity com- pared to POPC coatings; these viscous coatings resulted in the longest translocation times of lipid-anchored proteins that we could achieve to date. One limitation is that Archaea-inspired, monolayer-forming lipids are not readily available.

Venkatesen et al. applied the concept of coating nanopores in $\mathrm{SiN}_{x}$ membranes with lipid bilayers to coating nanopores in free-standing membranes of aluminum oxide $\left(\mathrm{Al}_{2} \mathrm{O}_{3}\right) \cdot{ }^{257}$ Specifically, the authors used the liposome rupture technique with high osmotic pressure in the presence of $\mathrm{Ca}^{2+}$ ions to coat $\mathrm{Al}_{2} \mathrm{O}_{3}$ that had been deposited by ALD. The deposition of lipid bilayers composed of 1,2-di-(9Z-octadecenoyl)-sn-glycero-3phosphocholine onto membranes with single nanopores increased the impedance from less or equal to $1 \mathrm{M} \Omega$ to more than $1 \mathrm{G} \Omega$ and allowed for the integration of a biological nanopore into the lipid membrane for the formation of a hybrid nanopore. $^{257}$

Hernández-Ainsa et al. showed that lipid coatings can also be applied onto the walls of nanopores in quartz nanocapillaries. ${ }^{258}$ In this case, the lipid bilayers increased the ratio of $\lambda$-DNA detection from $13 \%$ to $40 \%$ presumably due to the reduction of surface charges and minimization of non-specific adsorption of DNA to the coated capillary walls. ${ }^{258}$

Galla et al. demonstrated that applying a zwitterionic supported lipid bilayer to nanopores prepared with a helium-ion beam in silicon nitride membranes almost completely eliminated EOF. ${ }^{255}$ The authors threaded a single molecule of dsDNA through the pore with the help of optical tweezers and measured the effect of the lipid coating on the threading force. They found that the lipid coating almost completely eliminated EOF leading to an increase in threading force by $85 \% .^{255}$ Sischka et al. compared lipid-coated nanopores to carbon nano membranes (CNMs) and to uncoated silicon nitride membranes. ${ }^{256}$ These CNMs increased threading forces of DNA by $15 \%$ compared to uncoated membranes, showing a slight reduction in EOF, but this reduction was significantly smaller compared to the one enabled by lipid coatings.

When using nanopores in graphene for protein and nanoparticle translocation, Shan et al. detected gold nanoparticles after oxygen plasma treatment but they were not able to detect ferritin proteins after treatment of their graphene membranes with either oxygen plasma or mercaptohexadecanoic acid. ${ }^{260}$ In order to prevent ferritin adhesion to the pore walls, they modified their graphene membranes with the nanopore by immersion in an aqueous solution of the phospholipid-PEG

Table 2 Comparison of different lipid coatings with regard to their ability to form stable coatings with low current noise during nanopore recordings as well as their ability to slow down the speed of translocation of lipid-anchored analytes. Table from Eggenberger et al. ${ }^{114}$

\begin{tabular}{|c|c|c|c|c|}
\hline Lipid composition of coating & $\begin{array}{l}\text { Stable } \\
\text { baseline }\end{array}$ & $\begin{array}{l}\text { Low } \\
\text { noise }\end{array}$ & $\begin{array}{l}\text { Slow } \\
\text { translocation }\end{array}$ & $\begin{array}{l}\text { Straightforward } \\
\text { to coat }\end{array}$ \\
\hline $100 \%$ POPC & + & + & + & + \\
\hline 100\% Di-O-PhyPC & -- & -- & + & + \\
\hline $60 \%$ DOPC + $20 \%$ DOPE + $20 \%$ LysoPC & + & - & + & + \\
\hline $10,20,30,40 \%$ cholesterol $+90,80,70,60 \%$ POPC & + & + & + & + \\
\hline
\end{tabular}


amphiphile DPPE-PEG750; this treatment facilitated translocation and detection of ferritin but not BSA. ${ }^{260}$

To facilitate the free movement of proteins held within a nanopore by attaching them to a DNA-origami scaffold, ${ }^{261}$ Schmid et al. coated solid-state nanopores in $\operatorname{SiN}_{x}$ membranes with a lipid bilayer. In this set up the fluid lipid bilayer made it possible to observe a single molecule over extended times inside a nanopore while minimizing non-specific interactions with the pore wall. ${ }^{261}$

\section{Outlook}

The application of a coating to the walls of nanopores makes it possible to address many of limitations that come along with approaches for the detection and characterization of single molecules in synthetic nanopores. For instance, artifacts as a result of adhesion to the pore wall, ICR and EOF can be minimized or enhanced by choice of the appropriate coating. This review outlined the spectrum of approaches to nanopore coatings as well as the resulting benefits and opportunities. While no single coating technique solves all of the problems associated with solid-state nanopores - clogging, instability, unresolved translocation events, or success rate of preparing stable coatings of high quality still present challenges for many nanopore experiments - the coatings reviewed here increased the specificity, sensitivity, versatility, and information content from nanopore-based single molecule experiments. We hope that this overview will be helpful for solving or minimizing some of the problems that hamper the usefulness of nanopore-based analytics of complex, real world samples. ${ }^{275} \mathrm{We}$ predict that the nanopore field will continue to expand the strategies for increasing the functionality of nanopores ${ }^{300}$ and nanocapillaries ${ }^{301-303}$ and that coatings will play an essential role in this development. We expect to witness an increase, both in the number of ways how coatings will be applied, and in the fine-tuning of their molecular composition. Another development of interest may be coatings that enable and stabilize, hybrid biological-synthetic nanopores in which at least a selection of protein pores may be tightly embedded into a coated solid-state nanopore while maintaining their full functionality. ${ }^{304-311}$ Nanopores with coated walls will likely be useful for studies that manipulate or measure the forces acting on molecules during their translocating through pores, including studies that employ a combination of pressure and voltage $^{312}$ or laser-based trapping. ${ }^{313}$ Coatings may also become increasingly important for experiments that explore nanopores in membranes made from novel materials or for nanopore studies with unconventional or non-aqueous recording electrolytes or solutions. ${ }^{23,314-316}$ We are convinced that nanopore coatings will not only continue to improve the functionality of pores but will also provide a means to characterize the pores themselves, for instance with regard to their size and geometry. ${ }^{80,317}$ With improved coatings, we hope that nanopore-based biophysics and analytics will continue to make a growing contribution to our understanding of biological macromolecules and their interactions as well as to the detection of clinically-relevant biomarkers. ${ }^{318,319}$

\section{Conflicts of interest}

Michael Mayer is an inventor on a patent application about fluid lipid coatings for nanopore experiments.

\section{Acknowledgements}

This work was supported by Oxford Nanopore Technologies (Grant No. 350509-N016133) and the Swiss National Science Foundation (SNSF Grant No. 200021_169304).

\section{References}

1 S. Howorka and Z. Siwy, Nanopore analytics: sensing of single molecules, Chem. Soc. Rev., 2009, 38, 2360-2384.

2 T. Ito, L. Sun, R. R. Henriquez and R. M. Crooks, A Carbon Nanotube-Based Coulter Nanoparticle Counter, Acc. Chem. Res., 2004, 37, 937-945.

3 C. Dekker, Solid-state nanopores, Nat. Nanotechnol., 2007, 2, 209-215.

4 U. F. Keyser, Controlling molecular transport through nanopores, J. R. Soc., Interface, 2011, 8, 1369-1378.

5 W. Shi, A. K. Friedman and L. A. Baker, Nanopore Sensing, Anal. Chem., 2016, 89, 157-188.

6 D. Branton, et al., The potential and challenges of nanopore sequencing, Nat. Biotechnol., 2008, 26, 1146-1153.

7 D. Anselmetti, Nanopores: Tiny holes with great promise, Nat. Nanotechnol., 2012, 7, 81-82.

8 B. N. Miles, et al., Single molecule sensing with solid-state nanopores: novel materials, methods, and applications, Chem. Soc. Rev., 2012, 42, 15-28.

9 L. Movileanu, Interrogating single proteins through nanopores: challenges and opportunities, Trends Biotechnol., 2009, 27, 333-341.

10 L.-Q. Gu and J. W. Shim, Single molecule sensing by nanopores and nanopore devices, Analyst, 2010, 135, 441451.

11 B. M. Venkatesan and R. Bashir, Nanopore sensors for nucleic acid analysis, Nat. Nanotechnol., 2011, 6, 615-624.

12 M. Davenport, et al., The Role of Pore Geometry in Single Nanoparticle Detection, ACS Nano, 2012, 6, 8366-8380.

13 W.-J. Lan, D. A. Holden, B. Zhang and H. S. White, Nanoparticle Transport in Conical-Shaped Nanopores, Anal. Chem., 2011, 83, 3840-3847.

14 M. Jain, H. E. Olsen, B. Paten and M. Akeson, The Oxford Nanopore MinION: delivery of nanopore sequencing to the genomics community, Genome Biol., 2016, 17, 239.

15 M. Jain, et al., Nanopore sequencing and assembly of a human genome with ultra-long reads, Nat. Biotechnol., 2018, 36, 338-345. 
16 F. Nicoli, D. Verschueren, M. Klein, C. Dekker and M. P. Jonsson, DNA Translocations through Solid-State Plasmonic Nanopores, Nano Lett., 2014, 14, 6917-6925.

17 J. D. Spitzberg, A. Zrehen, X. F. van Kooten and A. Meller, Plasmonic-Nanopore Biosensors for Superior SingleMolecule Detection, Adv. Mater., 2019, 1900422.

18 H. Im, J. Wittenberg, N. Lesuffleur, A. C, N. Lindquist and S.-H. Oh, Membrane protein biosensing with plasmonic nanopore arrays and pore -spanning lipid membranes, Chem. Sci., 2010, 1, 688-696.

19 M. P. Jonsson and C. Dekker, Plasmonic Nanopore for Electrical Profiling of Optical Intensity Landscapes, Nano Lett., 2013, 13, 1029-1033.

20 M. Belkin, S.-H. Chao, M. P. Jonsson, C. Dekker and A. Aksimentiev, Plasmonic Nanopores for Trapping, Controlling Displacement, and Sequencing of DNA, ACS Nano, 2015, 9, 10598-10611.

21 O. N. Assad, et al., Light-Enhancing Plasmonic-Nanopore Biosensor for Superior Single-Molecule Detection, Adv. Mater., 2017, 29, 1605442.

22 C. R. Crick, et al., Low-Noise Plasmonic Nanopore Biosensors for Single Molecule Detection at Elevated Temperatures, ACS Photonics, 2017, 4, 2835-2842.

23 F. Traversi, et al., Detecting the translocation of DNA through a nanopore using graphene nanoribbons, Nat. Nanotechnol., 2013, 8, 939-945.

24 U. F. Keyser, et al., Direct force measurements on DNA in a solid-state nanopore, Nat. Phys., 2006, 2, 473-477.

25 N. Hacohen, C. J. X. Ip and R. Gordon, Analysis of Egg White Protein Composition with Double Nanohole Optical Tweezers, ACS Omega, 2018, 3, 5266-5272.

26 J. S. Daniels and N. Pourmand, Label-Free Impedance Biosensors: Opportunities and Challenges, Electroanalysis, 2007, 19, 1239-1257.

27 E. C. Yusko, et al., Real-time shape approximation and fingerprinting of single proteins using a nanopore, Nat. Nanotechnol., 2017, 12, 360-367.

28 L. Ma and S. L. Cockroft, Biological Nanopores for SingleMolecule Biophysics, ChemBioChem, 2010, 11, 25-34.

29 S. Majd, et al., Applications of biological pores in nanomedicine, sensing, and nanoelectronics, Curr. Opin. Biotechnol., 2010, 21, 439-476.

30 Y.-L. Ying, C. Cao and Y.-T. Long, Single molecule analysis by biological nanopore sensors, Analyst, 2014, 139, 3826-3835.

31 S. Majd, E. C. Yusko, A. D. MacBriar, J. Yang and M. Mayer, Gramicidin Pores Report the Activity of Membrane-Active Enzymes, J. Am. Chem. Soc., 2009, 131, 16119-16126.

32 S. Blake, T. Mayer, M. Mayer and J. Yang, Monitoring Chemical Reactions by Using Ion-Channel-Forming Peptides, ChemBioChem, 2006, 7, 433-435.

33 K. Lee, et al., Recent Progress in Solid-State Nanopores, Adv. Mater., 2018, 30, 1704680.

34 M. Mayer and J. Yang, Engineered Ion Channels as Emerging Tools for Chemical Biology, Acc. Chem. Res., 2013, 46, 2998-3008.
35 M. X. Macrae, et al., A Semi-Synthetic Ion Channel Platform for Detection of Phosphatase and Protease Activity, ACS Nano, 2009, 3, 3567-3580.

36 L. Song, et al., Structure of staphylococcal alpha-hemolysin, a heptameric transmembrane pore, Science, 1996, 274, 1859-1866.

37 G. Huang, A. Voet and G. Maglia, FraC nanopores with adjustable diameter identify the mass of opposite-charge peptides with 44 dalton resolution, Nat. Commun., 2019, 10, 835 .

38 S. K. Nomidis, J. Hooyberghs, G. Maglia and E. Carlon, DNA capture into the ClyA nanopore: diffusion-limited versus reaction-limited processes, J. Phys.: Condens. Matter, 2018, 30, 304001.

39 O. Braha, et al., Simultaneous stochastic sensing of divalent metal ions, Nat. Biotechnol., 2000, 18, 1005-1007.

40 G. Baaken, et al., High-Resolution Size-Discrimination of Single Nonionic Synthetic Polymers with a Highly Charged Biological Nanopore, ACS Nano, 2015, 9, 64436449.

41 R. Stefureac, Y. Long, H.-B. Kraatz, P. Howard and J. S. Lee, Transport of $\alpha$-Helical Peptides through $\alpha$-Hemolysin and Aerolysin Pores, Biochemistry, 2006, 45, 9172-9179.

42 F. Haque, J. Li, H.-C. Wu, X.-J. Liang and P. Guo, Solidstate and biological nanopore for real-time sensing of single chemical and sequencing of DNA, Nano Today, 2013, 8, 56-74.

43 G. Maglia, A. J. Heron, D. Stoddart, D. Japrung and H. Bayley, Chapter 22 - Analysis of Single Nucleic Acid Molecules with Protein Nanopores, in Methods in Enzymology, ed. N. G. Walter, Academic Press, 2010, vol. 475, pp. 591-623.

44 G. F. Schneider and C. Dekker, DNA sequencing with nanopores, Nat. Biotechnol., 2012, 30, 326-328.

45 M. Wanunu, Nanopores: A journey towards DNA sequencing, Phys. Life Rev., 2012, 9, 125-158.

46 Y. Wang, D. Zheng, Q. Tan, M. X. Wang and L.-Q. Gu, Nanopore-based detection of circulating microRNAs in lung cancer patients, Nat. Nanotechnol., 2011, 6, 668-674.

47 M. Mueller, U. Grauschopf, T. Maier, R. Glockshuber and N. Ban, The structure of a cytolytic $\alpha$-helical toxin pore reveals its assembly mechanism, Nature, 2009, 459, 726730 .

48 I. Iacovache, et al., Cryo-EM structure of aerolysin variants reveals a novel protein fold and the pore-formation process, Nat. Commun., 2016, 7, 12062.

49 A. A. Simpson, et al., Structure determination of the headtail connector of bacteriophage phi29, Acta Crystallogr., Sect. D: Biol. Crystallogr., 2001, 57, 1260-1269.

50 P. Goyal, et al., Structural and mechanistic insights into the bacterial amyloid secretion channel CsgG, Nature, 2014, 516, 250-253.

51 M. Faller, M. Niederweis and G. E. Schulz, The Structure of a Mycobacterial Outer-Membrane Channel, Science, 2004, 303, 1189-1192. 
52 K. Tanaka, J. M. M. Caaveiro, K. Morante, J. M. GonzálezMañas and K. Tsumoto, Structural basis for self-assembly of a cytolytic pore lined by protein and lipid, Nat. Commun., 2015, 6, 6337.

53 L.-Q. Gu, S. Cheley and H. Bayley, Prolonged Residence Time of a Noncovalent Molecular Adapter, $\beta$-Cyclodextrin, within the Lumen of Mutant $\alpha$-Hemolysin Pores, J. Gen. Physiol., 2001, 118, 481-494.

54 B. Walker and H. Bayley, Key Residues for Membrane Binding, Oligomerization, and Pore Forming Activity of Staphylococcal $\alpha$-Hemolysin Identified by Cysteine Scanning Mutagenesis and Targeted Chemical Modification, J. Biol. Chem., 1995, 270, 23065-23071.

55 C. Miller, Ion Channel Reconstitution, 1986.

$56 \mathrm{~J}$. Li, et al., Ion-beam sculpting at nanometre length scales, Nature, 2001, 412, 166-169.

57 J. D. Uram, K. Ke, A. J. Hunt and M. Mayer, Label-Free Affinity Assays by Rapid Detection of Immune Complexes in Submicrometer Pores, Angew. Chem., Int. Ed., 2006, 45, 2281-2285.

58 J. D. Uram, K. Ke, A. J. Hunt and M. Mayer, Submicrometer Pore-Based Characterization and Quantification of Antibody-Virus Interactions, Small, 2006, 2, 967-972.

59 L. J. de Vreede, et al., Wafer-scale fabrication of fused silica chips for low-noise recording of resistive pulses through nanopores, Nanotechnology, 2019, 30, 265301.

$60 \mathrm{~J}$. D. Uram and M. Mayer, Estimation of solid phase affinity constants using resistive-pulses from functionalized nanoparticles, Biosens. Bioelectron., 2007, 22, 15561560.

61 F. Bian, et al., Ultrasmall Silver Nanopores Fabricated by Femtosecond Laser Pulses, Nano Lett., 2011, 11, 3251-3257.

62 I. Perez, et al., TEM-Based Metrology for $\mathrm{HfO}_{2}$ Layers and Nanotubes Formed in Anodic Aluminum Oxide Nanopore Structures, Small, 2008, 4, 1223-1232.

$63 \mathrm{~J}$. Feng, et al., Electrochemical Reaction in Single Layer $\mathrm{MoS}_{2}$ : Nanopores Opened Atom by Atom, Nano Lett., 2015, 15, 3431-3438.

64 P. Actis, A. C. Mak and N. Pourmand, Functionalized nanopipettes: toward label-free, single cell biosensors, Bioanal. Rev., 2010, 1, 177-185.

65 B. M. Venkatesan, et al., Highly Sensitive, Mechanically Stable Nanopore Sensors for DNA Analysis, Adv. Mater., 2009, 21, 2771-2776.

66 R. An, et al., Ultrafast laser fabrication of submicrometer pores in borosilicate glass, Opt. Lett., 2008, 33, 1153-1155.

67 R. Torre, J. dela Larkin, A. Singer and A. Meller, Fabrication and characterization of solid-state nanopore arrays for high-throughput DNA sequencing, Nanotechnology, 2012, 23, 385308.

68 A. J. Storm, J. H. Chen, X. S. Ling, H. W. Zandbergen and C. Dekker, Fabrication of solid-state nanopores with single-nanometre precision, Nat. Mater., 2003, 2, 537-540.

69 X. Hou, W. Guo and L. Jiang, Biomimetic smart nanopores and nanochannels, Chem. Soc. Rev., 2011, 40, 23852401.
70 C. J. Lo, T. Aref and A. Bezryadin, Fabrication of symmetric sub-5 $\mathrm{nm}$ nanopores using focused ion and electron beams, Nanotechnology, 2006, 17, 3264.

71 J. Shim, J. A. Rivera and R. Bashir, Electron beam induced local crystallization of $\mathrm{HfO}_{2}$ nanopores for biosensing applications, Nanoscale, 2013, 5, 10887-10893.

72 M.-Y. Wu, D. Krapf, M. Zandbergen, H. Zandbergen and P. E. Batson, Formation of nanopores in a $\mathrm{SiN} / \mathrm{SiO}_{2}$ membrane with an electron beam, Appl. Phys. Lett., 2005, 87, 113106.

73 B. M. Venkatesan, A. B. Shah, J.-M. Zuo and R. Bashir, DNA Sensing Using Nanocrystalline Surface-Enhanced $\mathrm{Al}_{2} \mathrm{O}_{3}$ Nanopore Sensors, Adv. Funct. Mater., 2010, 20, 1266-1275.

74 L. T. Sexton, L. P. Horne and C. R. Martin, Developing synthetic conical nanopores for biosensing applications, Mol. Biosyst., 2007, 3, 667-685.

75 J. E. Wharton, et al., A Method for Reproducibly Preparing Synthetic Nanopores for Resistive-Pulse Biosensors, Small, 2007, 3, 1424-1430.

76 C. C. Harrell, S. B. Lee and C. R. Martin, Synthetic SingleNanopore and Nanotube Membranes, Anal. Chem., 2003, 75, 6861-6867.

77 P. Y. Apel, et al., Effect of nanosized surfactant molecules on the etching of ion tracks: New degrees of freedom in design of pore shape, Nucl. Instrum. Methods Phys. Res., Sect. B, 2003, 209, 329-334.

78 P. Scopece, L. A. Baker, P. Ugo and C. R. Martin, Conical nanopore membranes: solvent shaping of nanopores, Nanotechnology, 2006, 17, 3951.

79 H. Kwok, K. Briggs and V. Tabard-Cossa, Nanopore Fabrication by Controlled Dielectric Breakdown, PLoS One, 2014, 9, e92880.

80 C. Ying, et al., Formation of Single Nanopores with Diameters of 20-50 $\mathrm{nm}$ in Silicon Nitride Membranes Using Laser-Assisted Controlled Breakdown, ACS Nano, 2018, 12, 11458-11470.

81 T. Gilboa, E. Zvuloni, A. Zrehen, A. H. Squires and A. Meller, Automated, Ultra-Fast Laser-Drilling of Nanometer Scale Pores and Nanopore Arrays in Aqueous Solutions, Adv. Funct. Mater., 2019, 1900642.

82 H. Yamazaki, R. Hu, Q. Zhao and M. Wanunu, Photothermally Assisted Thinning of Silicon Nitride Membranes for Ultrathin Asymmetric Nanopores, ACS Nano, 2018, 12, 12472-12481.

$83 \mathrm{~J}$. Gao, et al., Layer-by-layer removal of insulating few-layer mica flakes for asymmetric ultra-thin nanopore fabrication, Nano Res., 2011, 5, 99-108.

84 N. Li, S. Yu, C. C. Harrell and C. R. Martin, Conical Nanopore Membranes, Preparation and Transport Properties, Anal. Chem., 2004, 76, 2025-2030.

85 G. F. Schneider, et al., DNA Translocation through Graphene Nanopores, Nano Lett., 2010, 10, 31633167.

86 M. J. Kim, M. Wanunu, D. C. Bell and A. Meller, Rapid Fabrication of Uniformly Sized Nanopores and Nanopore 
Arrays for Parallel DNA Analysis, Adv. Mater., 2006, 18, 3149-3153.

87 R. Wei, D. Pedone, A. Zürner, M. Döblinger and U. Rant, Fabrication of Metallized Nanopores in Silicon Nitride Membranes for Single-Molecule Sensing, Small, 2010, 6, 1406-1414.

88 J. Larkin, et al., Slow DNA Transport through Nanopores in Hafnium Oxide Membranes, ACS Nano, 2013, 7, 1012110128.

$89 \mathrm{~J}$. Yan, et al., Growth of Patterned Nanopore Arrays of Anodic Aluminum Oxide, Adv. Mater., 2003, 15, 2015-2018.

90 C. J. Russo and J. A. Golovchenko, Atom-by-atom nucleation and growth of graphene nanopores, Proc. Natl. Acad. Sci. U. S. A., 2012, 109, 5953-5957.

91 Z. S. Siwy and M. Davenport, Nanopores: Graphene opens up to DNA, Nat. Nanotechnol., 2010, 5, 697-698.

92 J. D. Uram, K. Ke and M. Mayer, Noise and Bandwidth of Current Recordings from Submicrometer Pores and Nanopores, ACS Nano, 2008, 2, 857-872.

93 W. Bell, N. A, et al., Multiplexed ionic current sensing with glass nanopores, Lab Chip, 2013, 13, 1859-1862.

94 B. Zhang, et al., Bench-Top Method for Fabricating GlassSealed Nanodisk Electrodes, Glass Nanopore Electrodes, and Glass Nanopore Membranes of Controlled Size, Anal. Chem., 2007, 79, 4778-4787.

95 A. Mara, Z. Siwy, C. Trautmann, J. Wan and F. Kamme, An Asymmetric Polymer Nanopore for Single Molecule Detection, Nano Lett., 2004, 4, 497-501.

96 B. Schiedt, K. Healy, A. P. Morrison, R. Neumann and Z. Siwy, Transport of ions and biomolecules through single asymmetric nanopores in polymer films, Nucl. Instrum. Methods Phys. Res., Sect. B, 2005, 236, 109116.

97 V. Hlady and J. Buijs, Protein adsorption on solid surfaces, Curr. Opin. Biotechnol., 1996, 7, 72-77.

98 Z. Siwy, I. D. Kosińska, A. Fuliński and C. R. Martin, Asymmetric Diffusion through Synthetic Nanopores, Phys. Rev. Lett., 2005, 94, 048102.

99 A. J. Storm, et al., Fast DNA translocation through a solidstate nanopore, Nano Lett., 2005, 5, 1193-1197.

100 D. Fologea, J. Uplinger, B. Thomas, D. S. McNabb and J. Li, Slowing DNA Translocation in a Solid-State Nanopore, Nano Lett., 2005, 5, 1734-1737.

101 W. Sparreboom, A. van den Berg and J. C. T. Eijkel, Principles and applications of nanofluidic transport, Nat. Nanotechnol., 2009, 4, 713-720.

102 A. Ramachandran, Y. Liu, W. Asghar and S. Iqbal, Characterization of DNA-Nanopore Interactions by Molecular Dynamics, Am. J. Biomed. Sci., 2009, 344-351, DOI: 10.5099/aj090400344.

103 S. Narayanan, A. G. Fedorov and Y. K. Joshi, Interfacial Transport of Evaporating Water Confined in Nanopores, Langmuir, 2011, 27, 10666-10676.

104 M. R. Powell, L. Cleary, M. Davenport, K. J. Shea and Z. S. Siwy, Electric-field-induced wetting and dewetting in single hydrophobic nanopores, Nat. Nanotechnol., 2011, 6, 798-802.

105 S. Vaitheeswaran and D. Thirumalai, Interactions between amino acid side chains in cylindrical hydrophobic nanopores with applications to peptide stability, Proc. Natl. Acad. Sci. U. S. A., 2008, 105, 17636-17641.

106 A. Aksimentiev, J. B. Heng, G. Timp and K. Schulten, Microscopic Kinetics of DNA Translocation through Synthetic Nanopores, Biophys. J., 2004, 87, 20862097.

107 E. C. Yusko, et al., Controlling protein translocation through nanopores with bio-inspired fluid walls, Nat. Nanotechnol., 2011, 6, 253-260.

108 M. R. Powell, et al., Nanoprecipitation-assisted ion current oscillations, Nat. Nanotechnol., 2008, 3, 51-57.

109 H. Daiguji, P. Yang and A. Majumdar, Ion Transport in Nanofluidic Channels, Nano Lett., 2004, 4, 137-142.

110 H. Daiguji, P. Yang, A. J. Szeri and A. Majumdar, Electrochemomechanical Energy Conversion in Nanofluidic Channels, Nano Lett., 2004, 4, 2315-2321.

111 D. V. Melnikov, Z. K. Hulings and M. E. Gracheva, Electroosmotic flow through nanopores in thin and ultrathin membranes, Phys. Rev. E, 2017, 95, 063105.

112 A. Asandei, et al., Electroosmotic Trap Against the Electrophoretic Force Near a Protein Nanopore Reveals Peptide Dynamics During Capture and Translocation, ACS Appl. Mater. Interfaces, 2016, 8, 13166-13179.

113 E. C. Yusko, Y. N. Billeh and M. Mayer, Current oscillations generated by precipitate formation in the mixing zone between two solutions inside a nanopore, J. Phys.: Condens. Matter, 2010, 22, 454127.

114 O. M. Eggenberger, et al., Fluid surface coatings for solidstate nanopores: comparison of phospholipid bilayers and archaea-Inspired lipid monolayers, Nanotechnology, 2019, 30, 325504.

115 Z. Siwy, E. Heins, C. C. Harrell, P. Kohli and C. R. Martin, Conical-Nanotube Ion-Current Rectifiers: The Role of Surface Charge, J. Am. Chem. Soc., 2004, 126, 1085010851.

116 H. S. White and A. Bund, Ion Current Rectification at Nanopores in Glass Membranes, Langmuir, 2008, 24, 2212-2218.

117 Y. Ai, M. Zhang, S. W. Joo, M. A. Cheney and S. Qian, Effects of Electroosmotic Flow on Ionic Current Rectification in Conical Nanopores, J. Phys. Chem. C, 2010, 114, 3883-3890.

118 J.-F. Pietschmann, et al., Rectification properties of conically shaped nanopores: consequences of miniaturization, 2012, ArXiv12094164 Cond-Mat Physicsphysics.

119 E. C. Yusko, R. An and M. Mayer, Electroosmotic Flow Can Generate Ion Current Rectification in Nano- and Micropores, ACS Nano, 2010, 4, 477-487.

120 M. X. Macrae, S. Blake, M. Mayer and J. Yang, Nanoscale Ionic Diodes with Tunable and Switchable Rectifying Behavior, J. Am. Chem. Soc., 2010, 132, 17661767. 
121 Z. S. Siwy, Ion-Current Rectification in Nanopores and Nanotubes with Broken Symmetry, Adv. Funct. Mater., 2006, 16, 735-746.

122 P. Y. Apel, Y. E. Korchev, Z. Siwy, R. Spohr and M. Yoshida, Diode-like single-ion track membrane prepared by electro-stopping, Nucl. Instrum. Methods Phys. Res., Sect. B, 2001, 184, 337-346.

123 I. Vlassiouk and Z. S. Siwy, Nanofluidic Diode, Nano Lett., 2007, 7, 552-556.

124 Y. Tian, X. Hou and L. Jiang, Biomimetic ionic rectifier systems: Asymmetric modification of single nanochannels by ion sputtering technology, J. Electroanal. Chem., 2011, 656, 231-236.

125 X. Hou, H. Dong, D. Zhu and L. Jiang, Fabrication of Stable Single Nanochannels with Controllable Ionic Rectification, Small, 2010, 6, 361-365.

126 Z. Zhang, et al., A Bioinspired Multifunctional Heterogeneous Membrane with Ultrahigh Ionic Rectification and Highly Efficient Selective Ionic Gating, Adv. Mater., 2016, 28, 144-150.

127 K. Kececi, L. T. Sexton, F. Buyukserin and C. R. Martin, Resistive-pulse detection of short dsDNAs using a chemically functionalized conical nanopore sensor, Nanomedicine, 2008, 3, 787-796.

128 Y. Xie, et al., Surface Modification of Single Track-Etched Nanopores with Surfactant CTAB, Langmuir, 2009, 25, 8870-8874.

129 B. N. Anderson, M. Muthukumar and A. Meller, $\mathrm{pH}$ Tuning of DNA Translocation Time through Organically Functionalized Nanopores, ACS Nano, 2013, 7, 1408-1414.

130 V. Thangaraj, et al., Detection of short ssDNA and dsDNA by current-voltage measurements using conical nanopores coated with $\mathrm{Al}_{2} \mathrm{O}_{3}$ by atomic layer deposition, Microchim. Acta, 2015, 183, 1011-1017.

131 E. Laarz, B. V. Zhmud and L. Bergström, Dissolution and Deagglomeration of Silicon Nitride in Aqueous Medium, J. Am. Ceram. Soc., 2000, 83, 2394-2400.

132 B. V. Zhmud and L. Bergström, Dissolution Kinetics of Silicon Nitride in Aqueous Suspension, J. Colloid Interface Sci., 1999, 218, 582-584.

133 S. W. Kowalczyk, T. R. Blosser and C. Dekker, Biomimetic nanopores: learning from and about nature, Trends Biotechnol., 2011, 29, 607-614.

134 X. Hou, H. Zhang and L. Jiang, Building Bio-Inspired Artificial Functional Nanochannels: From Symmetric to Asymmetric Modification, Angew. Chem., Int. Ed., 2012, 51, 5296-5307.

135 R. E. Gyurcsányi, Chemically-modified nanopores for sensing, TrAC, Trends Anal. Chem., 2008, 27, 627-639.

136 A. Kocer, L. Tauk and P. Déjardin, Nanopore sensors: From hybrid to abiotic systems, Biosens. Bioelectron., 2012, 38, 1-10.

137 M. Tagliazucchi and I. Szleifer, Transport mechanisms in nanopores and nanochannels: can we mimic nature? Mater, Today, 2015, 18, 131-142.
138 M. Lepoitevin, T. Ma, M. Bechelany, J.-M. Janot and S. Balme, Functionalization of single solid state nanopores to mimic biological ion channels: A review, Adv. Colloid Interface Sci., 2017, 250, 195-213.

139 G. Jeon, S. Y. Yang and J. K. Kim, Functional nanoporous membranes for drug delivery, J. Mater. Chem., 2012, 22, 14814-14834.

140 A. Asatekin and K. K. Gleason, Polymeric Nanopore Membranes for Hydrophobicity-Based Separations by Conformal Initiated Chemical Vapor Deposition, Nano Lett., 2011, 11, 677-686.

141 S. Banerjee, et al., Slowing DNA Transport Using Graphene-DNA Interactions, Adv. Funct. Mater., 2015, 25, 936-946.

142 P. Chen, et al., Atomic Layer Deposition to Fine-Tune the Surface Properties and Diameters of Fabricated Nanopores, Nano Lett., 2004, 4, 1333-1337.

143 Z. Chen, et al., DNA translocation through an array of kinked nanopores, Nat. Mater., 2010, 9, 667-675.

144 J. W. Elam, D. Routkevitch, P. P. Mardilovich and S. M. George, Conformal Coating on Ultrahigh-AspectRatio Nanopores of Anodic Alumina by Atomic Layer Deposition, Chem. Mater., 2003, 15, 3507-3517.

$145 \mathrm{~J}$. W. Elam, et al., Atomic Layer Deposition for the Conformal Coating of Nanoporous Materials, J. Nanomater., 2006, 2006, e64501.

146 R. Kox, C. Chen, G. Maes, L. Lagae and G. Borghs, Shrinking solid-state nanopores using electron-beaminduced deposition, Nanotechnology, 2009, 20, 115302.

147 R. Kox, et al., Local solid-state modification of nanopore surface charges, Nanotechnology, 2010, 21, 335703.

148 D. Coglitore, et al., Metal alloy solid-state nanopores for single nanoparticle detection, Phys. Chem. Chem. Phys., 2018, 20, 12799-12807.

149 P. Waduge, et al., Direct and Scalable Deposition of Atomically Thin Low-Noise $\mathrm{MoS}_{2}$ Membranes on Apertures, ACS Nano, 2015, 9, 7352-7359.

150 C. Wang, et al., Atomic Layer Deposition Modified TrackEtched Conical Nanochannels for Protein Sensing, Anal. Chem., 2015, 87, 8227-8233.

151 M. Weber, et al., Boron Nitride Nanoporous Membranes with High Surface Charge by Atomic Layer Deposition, ACS Appl. Mater. Interfaces, 2017, 9, 16669-16678.

152 E. B. Kalman, O. Sudre, I. Vlassiouk and Z. S. Siwy, Control of ionic transport through gated single conical nanopores, Anal. Bioanal. Chem., 2008, 394, 413-419.

153 C. Fan, et al., Achieving Uniform and Conformal ALD Coatings on Sub-10 nm Pores Using Dual-Stage Exposure/ Purge at Optimized Growth Temperatures, MRS Adv., 2018, 3, 2833-2839.

154 S. Zeng, et al., Controlled size reduction and its underlying mechanism to form solid-state nanopores via electron beam induced carbon deposition, Nanotechnology, 2019, 30, 455303.

$155 \mathrm{R} . \mathrm{Hu}$, et al., Intrinsic and membrane-facilitated $\alpha$-synuclein oligomerization revealed by label-free 
detection through solid-state nanopores, Sci. Rep., 2016, 6, 20776.

$156 \mathrm{X}$. Li, et al., Non-sticky translocation of bio-molecules through Tween 20-coated solid-state nanopores in a wide pH range, Appl. Phys. Lett., 2016, 109, 143105.

157 G. F. Schneider, et al., Tailoring the hydrophobicity of graphene for its use as nanopores for DNA translocation, Nat. Commun., 2013, 4, 2619.

158 P. Actis, et al., Reversible thrombin detection by aptamer functionalized STING sensors, Biosens. Bioelectron., 2011, 26, 4503-4507.

159 S. Umehara, et al., Current Rectification with Poly-lLysine-Coated Quartz Nanopipettes, Nano Lett., 2006, 6, 2486-2492.

160 P. Actis, O. Jejelowo and N. Pourmand, UltraSensitive Mycotoxin Detection by STING Sensors, Biosens. Bioelectron., 2010, 26, 333-337.

161 P. Actis, et al., Voltage-Controlled Metal Binding on Polyelectrolyte-Functionalized Nanopores, Langmuir, 2011, 27, 6528-6533.

162 B. Vilozny, P. Actis, R. A. Seger, Q. Vallmajo-Martin and N. Pourmand, Reversible Cation Response with a ProteinModified Nanopipette, Anal. Chem., 2011, 83, 6121-6126.

163 S. Umehara, M. Karhanek, R. W. Davis and N. Pourmand, Label-free biosensing with functionalized nanopipette probes, Proc. Natl. Acad. Sci. U. S. A., 2009, 106, 4611-4616.

164 H. Alem, F. Blondeau, K. Glinel, S. DemoustierChampagne and A. M. Jonas, Layer-by-Layer Assembly of Polyelectrolytes in Nanopores, Macromolecules, 2007, 40, 3366-3372.

165 M. Ali, et al., Layer-by-Layer Assembly of Polyelectrolytes into Ionic Current Rectifying Solid-State Nanopores: Insights from Theory and Experiment, J. Am. Chem. Soc., 2010, 132, 8338-8348.

166 E. L. C. J. Blundell, L. Mayne, M. Lickorish, S. Christie and M. Platt, Protein detection using Tunable Pores: Resistive Pulses and Current Rectification, Faraday Discuss., 2016, 193, 487-505.

167 M. Lepoitevin, et al., Fast and reversible functionalization of a single nanopore based on layer-by-layer polyelectrolyte self-assembly for tuning current rectification and designing sensors, RSC Adv., 2016, 6, 32228-32233.

168 Y. Zhao, J.-M. Janot, E. Balanzat and S. Balme, Mimicking pH-Gated Ionic Channels by Polyelectrolyte Complex Confinement Inside a Single Nanopore, Langmuir, 2017, 33, 3484-3490.

169 T. Ma, et al., Impact of Polyelectrolyte Multilayers on the Ionic Current Rectification of Conical Nanopores, Langmuir, 2018, 34, 3405-3412.

170 N. Das, R. Ray, S. Ray and C. R. Chaudhuri, Intelligent Quantification of Picomolar Protein Concentration in Serum by Functionalized Nanopores, IEEE Sens. J., 2018, 1-1, DOI: 10.1109/JSEN.2018.2872853.

171 N. Liu, et al., Photoregulation of Mass Transport through a Photoresponsive Azobenzene-Modified Nanoporous Membrane, Nano Lett., 2004, 4, 551-554.
172 M. Wanunu and A. Meller, Chemically Modified SolidState Nanopores, Nano Lett., 2007, 7, 1580-1585.

173 S. Ding, C. Gao and L.-Q. Gu, Capturing Single Molecules of Immunoglobulin and Ricin with an Aptamer-Encoded Glass Nanopore, Anal. Chem., 2009, 81, 6649-6655.

174 Y. Fu, H. Tokuhisa and L. A. Baker, Nanopore DNA sensors based on dendrimer-modified nanopipettes, Chem. Commun., 2009, 4877-4879, DOI: 10.1039/B910511E.

175 S. M. Iqbal, D. Akin and R. Bashir, Solid-state nanopore channels with DNA selectivity, Nat. Nanotechnol., 2007, 2, 243-248.

176 S. W. Kowalczyk, et al., Single-molecule transport across an individual biomimetic nuclear pore complex, Nat. Nanotechnol., 2011, 6, 433-438.

177 S. B. Lee, et al., Antibody-Based Bio-Nanotube Membranes for Enantiomeric Drug Separations, Science, 2002, 296, 2198-2200.

178 J. Nilsson, J. R. I. Lee, T. V. Ratto and S. E. Létant, Localized Functionalization of Single Nanopores, $A d v$. Mater., 2006, 18, 427-431.

179 S. Tan, L. Wang, H. Liu, H. Wu and Q. Liu, Single Nanoparticle Translocation Through Chemically Modified Solid Nanopore, Nanoscale Res. Lett., 2016, 11, 50.

180 G. Wang, B. Zhang, J. R. Wayment, J. M. Harris and H. S. White, Electrostatic-Gated Transport in Chemically Modified Glass Nanopore Electrodes, J. Am. Chem. Soc., 2006, 128, 7679-7686.

181 G. Wang, A. K. Bohaty, I. Zharov and H. S. White, Photon Gated Transport at the Glass Nanopore Electrode, J. Am. Chem. Soc., 2006, 128, 13553-13558.

182 L.-X. Zhang, S.-L. Cai, Y.-B. Zheng, X.-H. Cao and Y.-Q. Li, Smart Homopolymer Modification to Single Glass Conical Nanopore Channels: Dual-Stimuli-Actuated Highly Efficient Ion Gating, Adv. Funct. Mater., 2011, 21, 21032107.

183 V. Mussi, et al., "DNA-Dressed NAnopore" for complementary sequence detection, Biosens. Bioelectron., 2011, 29, 125-131.

184 N. Giamblanco, et al., Detection of protein aggregate morphology through single antifouling nanopore, Sens. Actuators, B, 2018, 260, 736-745.

185 S. Balme, et al., Unexpected ionic transport behavior in hydrophobic and uncharged conical nanopores, Faraday Discuss., 2018, 210, 69-85.

186 G.-C. Liu, et al., Ion-current-rectification-based customizable $\mathrm{pH}$ response in glass nanopipettes via silanization, Electrochem. Commun., 2018, 93, 95-99.

187 G.-C. Liu, et al., pH-modulated ion-current rectification in a cysteine-functionalized glass nanopipette, Electrochem. Commun., 2018, 97, 6-10.

188 A. Ananth, et al., Reversible Immobilization of Proteins in Sensors and Solid-State Nanopores, Small, 2018, 14, 1703357.

189 Y. Liebes-Peer, H. Rapaport and N. Ashkenasy, Amplification of Single Molecule Translocation Signal 
Using $\beta$-Strand Peptide Functionalized Nanopores, ACS Nano, 2014, 8, 6822-6832.

190 Z. Tang, et al., Surface Modification of Solid-State Nanopores for Sticky-Free Translocation of SingleStranded DNA, Small, 2014, 10, 4332-4339.

191 S. Zhang, et al., Detection of alkaline phosphatase activity with a functionalized nanopipette, Electrochem. Commun., 2019, 99, 71-74.

192 W. Guo, et al., Current Rectification in TemperatureResponsive Single Nanopores, ChemPhysChem, 2010, 11, 859-864.

193 H. He, X. Xu, P. Wang, L. Chen and Y. Jin, The facile surface chemical modification of a single glass nanopore and its use in the nonenzymatic detection of uric acid, Chem. Commun., 2015, 51, 1914-1917.

194 M. Nishizawa, V. P. Menon and C. R. Martin, Metal Nanotubule Membranes with Electrochemically Switchable Ion-Transport Selectivity, Science, 1995, 268, 700-702.

195 J. C. Hulteen, K. B. Jirage and C. R. Martin, Introducing Chemical Transport Selectivity into Gold Nanotubule Membranes, J. Am. Chem. Soc., 1998, 120, 6603-6604.

196 K. B. Jirage, J. C. Hulteen and C. R. Martin, Effect of Thiol Chemisorption on the Transport Properties of Gold Nanotubule Membranes, Anal. Chem., 1999, 71, 4913-4918.

197 S. B. Lee and C. R. Martin, pH-Switchable, IonPermselective Gold Nanotubule Membrane Based on Chemisorbed Cysteine, Anal. Chem., 2001, 73, 768-775.

198 C. R. Martin, M. Nishizawa, K. Jirage, M. Kang and S. B. Lee, Controlling Ion-Transport Selectivity in Gold Nanotubule Membranes, Adv. Mater., 2001, 13, 13511362.

199 S. Yu, S. B. Lee, M. Kang and C. R. Martin, Size-Based Protein Separations in Poly(ethylene glycol)-Derivatized Gold Nanotubule Membranes, Nano Lett., 2001, 1, 495-498.

200 P. Kohli, et al., DNA-Functionalized Nanotube Membranes with Single-Base Mismatch Selectivity, Science, 2004, 305, 984-986.

201 Z. Siwy, et al., Protein Biosensors Based on Biofunctionalized Conical Gold Nanotubes, J. Am. Chem. Soc., 2005, 127, 5000-5001.

202 L. T. Sexton, et al., Resistive-Pulse Studies of Proteins and Protein/Antibody Complexes Using a Conical Nanotube Sensor, J. Am. Chem. Soc., 2007, 129, 13144-13152.

203 T. Jovanovic-Talisman, et al., Artificial nanopores that mimic the transport selectivity of the nuclear pore complex, Nature, 2009, 457, 1023-1027.

204 R. Wei, V. Gatterdam, R. Wieneke, R. Tampé and U. Rant, Stochastic sensing of proteins with receptor-modified solid-state nanopores, Nat. Nanotechnol., 2012, 7, 257-263.

205 G. Emilsson, et al., Polymer brushes in solid-state nanopores form an impenetrable entropic barrier for proteins, Nanoscale, 2018, 10, 4663-4669.

206 G. Emilsson, et al., Gating Protein Transport in Solid State Nanopores by Single Molecule Recognition, ACS Cent. Sci., 2018, 4, 1007-1014.
207 X. Zambrana-Puyalto, et al., Site-selective functionalization of plasmonic nanopores for enhanced fluorescence emission rate and Förster resonance energy transfer, Nanoscale Adv., 2019, 1, 2454-2461.

208 Y. Pang and R. Gordon, Optical Trapping of a Single Protein, Nano Lett., 2012, 12, 402-406.

209 B. Malekian, et al., Detecting Selective Protein Binding Inside Plasmonic Nanopores: Toward a Mimic of the Nuclear Pore Complex, Front. Chem., 2018, 6, 637.

210 X. Hou, et al., A pH-Gating Ionic Transport Nanodevice: Asymmetric Chemical Modification of Single Nanochannels, Adv. Mater., 2010, 22, 2440-2443.

$211 \mathrm{X}$. Hou, et al., A Biomimetic Asymmetric Responsive Single Nanochannel, J. Am. Chem. Soc., 2010, 132, 11736-11742.

212 S. F. Buchsbaum, G. Nguyen, S. Howorka and Z. S. Siwy, DNA-Modified Polymer Pores Allow $\mathrm{pH}$ - and VoltageGated Control of Channel Flux, J. Am. Chem. Soc., 2014, 136, 9902-9905.

213 M. Lepoitevin, M. Bechelany, E. Balanzat, J.-M. Janot and S. Balme, Non-Fluorescence label protein sensing with track-etched nanopore decorated by avidin/biotin system, Electrochim. Acta, 2016, 211, 611-618.

214 M. Lepoitevin, et al., Combining a sensor and a pH-gated nanopore based on an avidin-biotin system, Chem. Commun., 2015, 51, 5994-5997.

215 B. Yameen, et al., Ionic Transport Through Single SolidState Nanopores Controlled with Thermally Nanoactuated Macromolecular Gates, Small, 2009, 5, 1287-1291.

216 B. Yameen, et al., Synthetic Proton-Gated Ion Channels via Single Solid-State Nanochannels Modified with Responsive Polymer Brushes, Nano Lett., 2009, 9, 27882793.

217 M. Ali, R. Neumann and W. Ensinger, Sequence-Specific Recognition of DNA Oligomer Using Peptide Nucleic Acid (PNA)-Modified Synthetic Ion Channels: PNA/DNA Hybridization in Nanoconfined Environment, ACS Nano, 2010, 4, 7267-7274.

218 M. Ali, S. Nasir and W. Ensinger, Bioconjugation-induced ionic current rectification in aptamer-modified single cylindrical nanopores, Chem. Commun., 2015, 51, 34543457.

219 M. Ali, S. Mafe, P. Ramirez, R. Neumann and W. Ensinger, Logic Gates Using Nanofluidic Diodes Based on Conical Nanopores Functionalized with Polyprotic Acid Chains, Langmuir, 2009, 25, 11993-11997.

220 M. Ali, B. Schiedt, R. Neumann and W. Ensinger, Biosensing with Functionalized Single Asymmetric Polymer Nanochannels, Macromol. Biosci., 2010, 10, 2832.

221 M. Ali, Q. H. Nguyen, R. Neumann and W. Ensinger, ATPmodulated ionic transport through synthetic nanochannels, Chem. Commun., 2010, 46, 6690-6692.

222 M. Ali, et al., Biomolecular conjugation inside synthetic polymer nanopores viaglycoprotein-lectin interactions, Nanoscale, 2011, 3, 1894-1903. 
223 M. Ali, et al., Hydrogen Peroxide Sensing with Horseradish Peroxidase-Modified Polymer Single Conical Nanochannels, Anal. Chem., 2011, 83, 1673-1680.

224 M. Ali, et al., Metal Ion Affinity-based Biomolecular Recognition and Conjugation inside Synthetic Polymer Nanopores Modified with Iron-Terpyridine Complexes, J. Am. Chem. Soc., 2011, 133, 17307-17314.

225 S. Nasir, M. Ali and W. Ensinger, Thermally controlled permeation of ionic molecules through synthetic nanopores functionalized with amine-terminated polymer brushes, Nanotechnology, 2012, 23, 225502.

226 M. Ali, et al., Single cigar-shaped nanopores functionalized with amphoteric amino acid chains: experimental and theoretical characterization, ACS Nano, 2012, 6, 3631-3640.

227 M. Ali, et al., Calcium Binding and Ionic Conduction in Single Conical Nanopores with Polyacid Chains: Model and Experiments, ACS Nano, 2012, 6, 9247-9257.

228 M. N. Tahir, et al., Silicatein conjugation inside nanoconfined geometries through immobilized NTA-Ni(II) chelates, Chem. Commun., 2013, 49, 2210-2212.

229 M. Ali, et al., Carbohydrate-Mediated Biomolecular Recognition and Gating of Synthetic Ion Channels, J. Phys. Chem. C, 2013, 117, 18234-18242.

230 M. Ali, S. Nasir, I. Ahmed, L. Fruk and W. Ensinger, Tuning nanopore surface polarity and rectification properties through enzymatic hydrolysis inside nanoconfined geometries, Chem. Commun., 2013, 49, 8770-8772.

231 M. Ali, S. Nasir and W. Ensinger, Stereoselective detection of amino acids with protein-modified single asymmetric nanopores, Electrochim. Acta, 2016, 215, 231-237.

232 M. Ali, et al., Label-free histamine detection with nanofluidic diodes through metal ion displacement mechanism, Colloids Surf., B, 2017, 150, 201-208.

233 M. Ali, et al., A redox-sensitive nanofluidic diode based on nicotinamide-modified asymmetric nanopores, Sens. Actuators, B, 2017, 240, 895-902.

234 M. Ali, et al., Potassium-induced ionic conduction through a single nanofluidic pore modified with acyclic polyether derivative, Anal. Chim. Acta, 2018, 1039, 132-139.

235 F. Xia, et al., Gating of Single Synthetic Nanopores by Proton-Driven DNA Molecular Motors, J. Am. Chem. Soc., 2008, 130, 8345-8350.

$236 \mathrm{X}$. Hou, et al., A Biomimetic Potassium Responsive Nanochannel: G-Quadruplex DNA Conformational Switching in a Synthetic Nanopore, J. Am. Chem. Soc., 2009, 131, 7800-7805.

237 Y. Tian, et al., A biomimetic zinc activated ion channel, Chem. Commun., 2010, 46, 1682-1684.

238 W. Guo, et al., Integrating Ionic Gate and Rectifier Within One Solid-State Nanopore via Modification with DualResponsive Copolymer Brushes, Adv. Funct. Mater., 2010, 20, 3561-3567.

239 M. Zhang, et al., Light and pH Cooperative Nanofluidic Diode Using a Spiropyran-Functionalized Single Nanochannel, Adv. Mater., 2012, 24, 2424-2428.
240 Z. Zhang, et al., Asymmetric Multifunctional Heterogeneous Membranes for $\mathrm{pH}^{-}$and Temperature-Cooperative Smart Ion Transport Modulation, Adv. Mater., 2016, 28, 96139619.

241 E. B. Kalman, I. Vlassiouk and Z. S. Siwy, Nanofluidic Bipolar Transistors, Adv. Mater., 2008, 20, 293-297.

242 I. Vlassiouk, T. R. Kozel and Z. S. Siwy, Biosensing with Nanofluidic Diodes, J. Am. Chem. Soc., 2009, 131, 82118220.

243 G. Nguyen, S. Howorka and Z. S. Siwy, DNA Strands Attached Inside Single Conical Nanopores: Ionic Pore Characteristics and Insight into DNA Biophysics, J. Membr. Biol., 2011, 239, 105-113.

244 M. Ali, et al., Biosensing and Supramolecular Bioconjugation in Single Conical Polymer Nanochannels. Facile Incorporation of Biorecognition Elements into Nanoconfined Geometries, J. Am. Chem. Soc., 2008, 130, 16351-16357.

245 M. Tagliazucchi, O. Azzaroni and I. Szleifer, Responsive Polymers End-Tethered in Solid-State Nanochannels: When Nanoconfinement Really Matters, J. Am. Chem. Soc., 2010, 132, 12404-12411.

246 T. Ma, et al., Combining Light-Gated and pH-Responsive Nanopore Based on PEG-Spiropyran Functionalization, Adv. Mater. Interfaces, 2018, 5, 1701051.

247 N. Giamblanco, et al., Amyloid Growth, Inhibition, and Real-Time Enzymatic Degradation Revealed with Single Conical Nanopore, Anal. Chem., 2018, 90, 12900-12908.

248 D. Wang, et al., Regulating the Transport of DNA through Biofriendly Nanochannels in a Thin Solid Membrane, Sci. Rep., 2014, 4, 3985.

249 B. Yameen, et al., Single Conical Nanopores Displaying pH-Tunable Rectifying Characteristics. Manipulating Ionic Transport With Zwitterionic Polymer Brushes, J. Am. Chem. Soc., 2009, 131, 2070-2071.

250 B. Yameen, et al., Proton-regulated rectified ionic transport through solid-state conical nanopores modified with phosphate-bearing polymer brushes, Chem. Commun., 2010, 46, 1908-1910.

251 A. Brunsen, et al., Proton and Calcium-Gated Ionic Mesochannels: Phosphate-Bearing Polymer Brushes Hosted in Mesoporous Thin Films As Biomimetic Interfacial Architectures, Langmuir, 2012, 28, 3583-3592.

252 I. W. Leong, et al., Back-Side Polymer-Coated SolidState Nanopore Sensors, ACS Omega, 2019, 4, 1256112566.

253 Y. M. N. D. Y. Bandara, B. I. Karawdeniya, J. T. Hagan, R. B. Chevalier and J. R. Dwyer, Chemically Functionalizing Controlled Dielectric Breakdown Silicon Nitride Nanopores by Direct Photohydrosilylation, ACS Appl. Mater. Interfaces, 2019, 11, 30411-30420.

254 Y. Youn, et al., Selective Detection of Single-Stranded DNA Molecules Using a Glass Nanocapillary Functionalized with DNA, Anal. Chem., 2016, 88, 688-694.

255 L. Galla, et al., Hydrodynamic Slip on DNA Observed by Optical Tweezers-Controlled Translocation Experiments 
with Solid-State and Lipid-Coated Nanopores, Nano Lett., 2014, 14, 4176-4182.

256 A. Sischka, et al., Controlled translocation of DNA through nanopores in carbon nano-, silicon-nitride- and lipidcoated membranes, Analyst, 2015, 140, 4843-4847.

257 B. M. Venkatesan, et al., Lipid bilayer coated $\mathrm{Al}_{2} \mathrm{O}_{3}$ nanopore sensors: towards a hybrid biological solid-state nanopore, Biomed. Microdevices, 2011, 13, 671-682.

258 S. Hernández-Ainsa, et al., Lipid-coated nanocapillaries for DNA sensing, Analyst, 2012, 138, 104-106.

259 E. C. Yusko, et al., Single-Particle Characterization of A $\beta$ Oligomers in Solution, ACS Nano, 2012, 6, 5909-5919.

260 Y. P. Shan, et al., Surface modification of graphene nanopores for protein translocation, Nanotechnology, 2013, 24, 495102.

261 S. Schmid, P. Stoemmer, H. Dietz and C. Dekker, High Bandwidth Sensing of Single Protein Dynamics using Nanopores and DNA Origami, Biophys. J., 2019, 116, 341a342a.

262 S. M. George, Atomic Layer Deposition: An Overview, Chem. Rev., 2010, 110, 111-131.

263 M. J. Hampden-Smith and T. T. Kodas, Chemical vapor deposition of metals: Part 1. An overview of CVD processes, Chem. Vap. Deposition, 1995, 1, 8-23.

264 C.-M. Wang, D.-L. Kong, Q. Chen and J.-M. Xue, Surface engineering of synthetic nanopores by atomic layer deposition and their applications, Front. Mater. Sci., 2013, 7, 335-349.

265 H. W. P. Koops, R. Weiel, D. P. Kern and T. H. Baum, High-resolution electron-beam induced deposition, J. Vac. Sci. Technol., B: Microelectron. Process. Phenom., 1988, 6, 477-481.

266 W. F. van Dorp and C. W. Hagen, A critical literature review of focused electron beam induced deposition, J. Appl. Phys., 2008, 104, 081301.

267 R. Rollings, et al., The effects of geometry and stability of solid-state nanopores on detecting single DNA molecules, Nanotechnology, 2015, 26, 044001.

268 G. F. Eriksen and K. Dyrbye, Protective coatings in harsh environments, J. Micromech. Microeng., 1996, 6, 55.

269 M. van den Hout, et al., Controlling nanopore size, shape and stability, Nanotechnology, 2010, 21, 115304.

270 M. Vogt and R. Hauptmann, Plasma-deposited passivation layers for moisture and water protection, Surf. Coat. Technol., 1995, 74-75, 676-681.

271 B. Yin, et al., Covalent Modification of Silicon Nitride Nanopore by Amphoteric Polylysine for Short DNA Detection, ACS Omega, 2017, 2, 7127-7135.

272 M. J. Rosen and D. J. T. Kunjappu, Surfactants and Interfacial Phenomena, John Wiley \& Sons, 2012.

273 J. Salager, Surfactants: Types and uses, 2002.

274 S. Paria and K. C. Khilar, A review on experimental studies of surfactant adsorption at the hydrophilic solid-water interface, Adv. Colloid Interface Sci., 2004, 110, 75-95.

275 J. Houghtaling, J. List and M. Mayer, Nanopore-Based Rapid Characterization of Individual Amyloid Particles in
Solution: Concepts, Challenges, and Prospects, Small, 2018, 14, 1802412.

276 R. K. Iler, Multilayers of colloidal particles, J. Colloid Interface Sci., 1966, 21, 569-594.

277 G. Decher and J.-D. Hong, Buildup of ultrathin multilayer films by a self-assembly process, 1 consecutive adsorption of anionic and cationic bipolar amphiphiles on charged surfaces, Makromol. Chem., Macromol. Symp., 1991, 46, 321-327.

278 G. Decher and J. D. Hong, Buildup of Ultrathin Multilayer Films by a Self-Assembly Process: II. Consecutive Adsorption of Anionic and Cationic Bipolar Amphiphiles and Polyelectrolytes on Charged Surfaces, Ber. Bunsenges. Phys. Chem., 1991, 95, 1430-1434.

279 G. Decher, J. D. Hong and J. Schmitt, Buildup of ultrathin multilayer films by a self-assembly process: III. Consecutively alternating adsorption of anionic and cationic polyelectrolytes on charged surfaces, Thin Solid Films, 1992, 210, 831-835.

280 Z. Tang, Y. Wang, P. Podsiadlo and N. A. Kotov, Biomedical Applications of Layer-by-Layer Assembly: From Biomimetics to Tissue Engineering, Adv. Mater., 2006, 18, 3203-3224.

281 J. J. Richardson, et al., Innovation in Layer-by-Layer Assembly, Chem. Rev., 2016, 116, 14828-14867.

282 A Silane Primer: Chemistry and Applications of AIkoxy Silanes. ResearchGate Available at: https://www.researchgate. net/publication/237302419_A_Silane_Primer_Chemistry_ and_Applications_of_AIkoxy_Silanes. (Accessed: 29th May 2017).

283 J. B. Brzoska, I. B. Azouz and F. Rondelez, Silanization of Solid Substrates: A Step Toward Reproducibility, Langmuir, 1994, 10, 4367-4373.

284 D. Kowalczyk, S. Slomkowski, M. M. Chehimi and M. Delamar, Adsorption of aminopropyltriethoxy silane on quartz: an XPS and contact angle measurements study, Int. J. Adhes. Adhes., 1996, 16, 227-232.

285 I. Lee and R. P. Wool, Controlling amine receptor group density on aluminum oxide surfaces by mixed silane self assembly, Thin Solid Films, 2000, 379, 94-100.

286 E. K. U. Larsen, et al., Size-Dependent Accumulation of PEGylated Silane-Coated Magnetic Iron Oxide Nanoparticles in Murine Tumors, ACS Nano, 2009, 3, 1947-1951.

287 S. I. Raider, R. Flitsch, J. A. Aboaf and W. A. Pliskin, Surface Oxidation of Silicon Nitride Films, J. Electrochem. Soc., 1976, 123, 560-565.

288 J. C. Love, L. A. Estroff, J. K. Kriebel, R. G. Nuzzo and G. M. Whitesides, Self-Assembled Monolayers of Thiolates on Metals as a Form of Nanotechnology, Chem. Rev., 2005, 105, 1103-1170.

289 E. Ostuni, R. G. Chapman, R. E. Holmlin, S. Takayama and G. M. Whitesides, A Survey of Structure-Property Relationships of Surfaces that Resist the Adsorption of Protein, Langmuir, 2001, 17, 5605-5620.

290 C. Vericat, M. E. Vela, G. Benitez, P. Carro and R. C. Salvarezza, Self-assembled monolayers of thiols and 
dithiols on gold: new challenges for a well-known system, Chem. Soc. Rev., 2010, 39, 1805-1834.

291 A. Ulman, Formation and Structure of Self-Assembled Monolayers, Chem. Rev., 1996, 96, 1533-1554.

292 G. M. Whitesides, J. K. Kriebel and J. C. Love, Molecular engineering of surfaces using self-assembled monolayers, Sci. Prog., 2005, 88, 17-48.

293 D. Chen, et al., Low-Potential Detection of Endogenous and Physiological Uric Acid at Uricase-Thionine-SingleWalled Carbon Nanotube Modified Electrodes, Anal. Chem., 2010, 82, 2448-2455.

294 L. R. Wetter and H. F. Deutsch, Immunological Studies on Egg White Proteins Iv. Immunochemical and Physical Studies of Lysozyme, J. Biol. Chem., 1951, 192, 237-242.

295 J. Houghtaling, et al., Estimation of Shape, Volume, and Dipole Moment of Individual Proteins Freely Transiting a Synthetic Nanopore, ACS Nano, 2019, 13, 5231-5242.

296 T. Ando, et al., Nanopore formation in the cuticle of an insect olfactory sensillum, 2019, bioRxiv 444729. DOI: DOI: $10.1101 / 444729$.

297 T. B. H. Schroeder, J. Houghtaling, B. D. Wilts and M. Mayer, It's Not a Bug, It's a Feature: Functional Materials in Insects, Adv. Mater., 2018, 30, e1705322.

298 M. G. Zagorski, et al., Amyloid Abeta-the Peptide from Hell, Regul. Pept., 2001, 97, 16.

299 M. Locke, Permeability of Insect Cuticle to Water and Lipids, Science, 1965, 147, 295-298.

300 A. Kleefen, et al., Multiplexed Parallel Single Transport Recordings on Nanopore Arrays, Nano Lett., 2010, 10, 50805087.

301 L. J. Steinbock, A. Lucas, O. Otto and U. F. Keyser, Voltage-driven transport of ions and DNA through nanocapillaries, Electrophoresis, 2012, 33, 3480-3487.

302 Z. Wang, et al., Nanopipettes: a potential tool for DNA detection, Analyst, 2019, 144, 5037-5047.

303 L. Xue, et al., Gated Single-Molecule Transport in DoubleBarreled Nanopores, ACS Appl. Mater. Interfaces, 2018, 10, 38621-38629.

304 A. Abou Chaaya, et al., Enhanced Ionic Transport Mechanism by Gramicidin A Confined Inside Nanopores Tuned by Atomic Layer Deposition, J. Phys. Chem. C, 2013, 117, 15306-15315.

305 F. Picaud, et al., Enhanced potassium selectivity in a bioinspired solid nanopore, Phys. Chem. Chem. Phys., 2013, 15, 19601-19607.

306 S. Balme, et al., Controlling potassium selectivity and proton blocking in a hybrid biological/solid-state polymer nanoporous membrane, Nanoscale, 2013, 5, 3961-3968.

307 S. Cabello-Aguilar, et al., Slow translocation of polynucleotides and their discrimination by $\alpha$-hemolysin inside a single track-etched nanopore designed by atomic layer deposition, Nanoscale, 2013, 5, 9582-9586.

308 S. Balme, M. Lepoitevin, M. Bechelany and J. M. Janot, Hybrid biological/artificial nanopore, in Physics, Chemistry and Applications of Nanostructures, World Scientific, 2015, pp. 454-456. DOI: 10.1142/9789814696524_0112.

309 A. R. Hall, et al., Hybrid pore formation by directed insertion of $\alpha$-haemolysin into solid-state nanopores, Nat. Nanotechnol., 2010, 5, 874-877.

310 S. Balme, et al., New Bioinspired Membrane Made of a Biological Ion Channel Confined into the Cylindrical Nanopore of a Solid-State Polymer, Nano Lett., 2011, 11, 712-716.

311 R. J. White, et al., Single Ion-Channel Recordings Using Glass Nanopore Membranes, J. Am. Chem. Soc., 2007, 129, 11766-11775.

312 D. P. Hoogerheide, B. Lu and J. A. Golovchenko, PressureVoltage Trap for DNA near a Solid-State Nanopore, ACS Nano, 2014, 8, 7384-7391.

313 N. Di Fiori, et al., Optoelectronic control of surface charge and translocation dynamics in solid-state nanopores, Nat. Nanotechnol., 2013, 8, 946-951.

314 X. Hou, Y. Hu, A. Grinthal, M. Khan and J. Aizenberg, Liquid-based gating mechanism with tunable multiphase selectivity and antifouling behaviour, Nature, 2015, 519, 70-73.

315 M. Waugh, et al., Interfacing solid-state nanopores with gel media to slow DNA translocations, Electrophoresis, 2015, 36, 1759-1767.

316 M. Davenport, A. Rodriguez, K. J. Shea and Z. S. Siwy, Squeezing Ionic Liquids through Nanopores, Nano Lett., 2009, 9, 2125-2128.

317 C. M. Frament, N. Bandara and J. R. Dwyer, Nanopore Surface Coating Delivers Nanopore Size and Shape through Conductance-Based Sizing, ACS Appl. Mater. Interfaces, 2013, 5, 9330-9337.

318 S. H. Petrosko, R. Johnson, H. White and C. A. Mirkin, Nanoreactors: Small Spaces, Big Implications in Chemistry, J. Am. Chem. Soc., 2016, 138, 7443-7445.

319 S. Balme, M. Lepoitevin, L. F. Dumée, M. Bechelany and J.-M. Janot, Diffusion dynamics of latex nanoparticles coated with ssDNA across a single nanopore, Soft Matter, 2017, 13, 496-502. 